\title{
La(s) geopolítica(s) de los recursos naturales en la Sierra de Santa Marta (Veracruz, México): prácticas alternativas para la sustentabilidad y resistencias indígenas al modelo desarrollista*
}

\author{
Jesús MORENO ARRIBA \\ Departamento de Antropología Social y Cultural \\ Universidad Nacional de Educación a Distancia \\ jmorenoarriba@hotmail.com
}

Recibido: 08-01-2015

Aceptado: 18-03-2015

\begin{abstract}
RESUMEN
En este artículo se presenta desde un enfoque de(s)colonial el actual marco geopolítico de la gestión de los recursos naturales en las comunidades indígenas campesinas de nahuas y popolucas en la Sierra de Santa Marta en Veracruz (México). Este contexto se caracteriza por la emergencia de diversas experiencias integrales, sustentables e interculturales de manejo de recursos naturales. Estos incipientes proyectos, a partir de la implementación de una metodología de investigación cualitativa, de su correlación epistemológica con los modelos alternativos al desarrollo, surgido como una fuerza hegemónica en la posguerra mundial, y de su vinculación con otras formas económicas no capitalistas, se revelan como prácticas socioespaciales alternativas en las luchas y resistencias indígenas por mejorar la sustentabilidad integral (ecológica, económica y social) de los pueblos originarios de Mesoamérica, en oposición a décadas de marcados fracasos de los programas impuestos desde el modelo desarrollista, de tipo asistencialista y paternalista.
\end{abstract}

Palabras clave: territorios originarios; recursos naturales; alternativas al desarrollismo; resistencias indígenas; sustentabilidad integral.

\footnotetext{
* Investigación llevada a cabo como beneficiario de una Beca MAEC-AECID (2011-2013), concedida por la Agencia Española de Cooperación Internacional para el Desarrollo (AECID) a españoles, para estudios de postgrado, doctorado e investigación en universidades y centros superiores extranjeros de reconocido prestigio en países de ayuda oficial al desarrollo. Este artículo se enmarca dentro de los resultados científicos del proyecto de investigación posdoctoral en Geografía bajo el título de Comunalismo agrario, solidaridad y perspectivas de desarrollo sostenible en las comunidades castellano-leonesas (España) y veracruzanas (México) y, a su vez, también forma parte de los avances de investigación de la tesis doctoral en Antropología Social y Cultural titulada La gestión de recursos naturales en la Sierra de Santa Marta en Veracruz (México): un ejemplo de alianza estratégica de saberes locales y conocimientos técnico-científicos para la sustentabilidad, inscrita en el Departamento de Antropología Social y Cultural de la Facultad de Filosofía de la Universidad Nacional de Educación a Distancia (UNED).
} 


\title{
The Geopolitics of Natural Resources in the Sierra of Santa Marta (Veracruz, Mexico): Alternative Practices for Sustainability and Indigenous Resistance against the Developmentalist Model
}

\begin{abstract}
From a decolonial perspective, this article examines the geopolitical framework that affects currently the management of natural resources in the peasant indigenous communities of nahuas and popolucas in the Sierra of Santa Marta (Veracruz, Mexico). The context is characterized by the emergence of different experiences defined by the integral, sustainable and intercultural management of natural resources. The article is based on a qualitative methodology of research and an epistemology that distances itself from developmental models - hegemonic in the aftermath of the Second World War-, and thus linked to noncapitalist economic forms. These incipient projects take the shape of alternative socio-political practices in the struggles and resistances of the communities that fight for the improvement of the integral sustainability (ecological, economic and social) of the indigenous peoples of Mesoamerica. This stands in stark contrast to decades of resounding failures resultant from developmentalist-like programs, defined by their assistancerelated and paternalistic focus.
\end{abstract}

Key words: indigenous territories; natural resources; alternatives to developmentalism; indigenous resistance; comprehensive sustainability.

\section{A geopolítica dos recursos naturais na Serra de Santa Marta (Veracruz, México): práticas alternativas para a sustentabilidade e resistência indígena ao modelo desenvolvimentista}

\begin{abstract}
RESUMO
Neste artigo é apresentado a partir de uma abordagem descolonial o contexto geopolítico atual da gestão dos recursos naturais em comunidades indígenas e camponesas Nahuas e Popolucas da Serra de Santa Marta em Veracruz (México). Esse contexto é caracterizado pelo surgimento de várias experiências integradas, sustentáveis e interculturais de gestão dos recursos naturais. Estes projetos emergentes, a partir da implementação de uma metodologia de pesquisa qualitativa, sua correlação epistemológica com modelos alternativos ao desenvolvimento emergiu como uma força hegemônica após a Segunda Guerra Mundial, e sua relação com outras formas de relações econômicas não capitalistas, revelam-se como práticas sócio-espaciais alternativas em as lutas e resistências indígenas para melhorar a sustentabilidade global (ecológica, económica e social) dos povos originários da Mesoamérica, ao contrário de décadas de fracassos marcantes de programas impostos a partir do modelo de desenvolvimento de tipo assistencialista e paternalista.
\end{abstract}

Palavras-chave: territórios indígenas; recursos naturais; alternativas ao desenvolvimentismo; resistência indígena; sustentabilidade integral.

\section{REFERENCIA NORMALIZADA}

Moreno Arriba, Jesús (2015) "La(s) geopolítica(s) de los recursos naturales en la Sierra de Santa Marta (Veracruz, México): prácticas alternativas para la sustentabilidad y resistencias indígenas al modelo desarrollista”. Geopolítica(s). Revista de estudios sobre espacio y poder, vol. 6, núm. 1, 39-82.

SUMARIO: 1 . Introducción: imaginación socioespacial y reconstrucción de la economía frente a la crisis del desarrollo. 1.1. La necesaria reconstrucción de la economía convencional. 1.2. La nueva lógica de los márgenes del sistema y las culturas substantivas invisibilizadas por la meta del discurso desarrollista. 1.3. 
Geometría del poder y nuevas geografías de la responsabilidad. 1.4. Las iniciativas poseconómicas: propuestas posibles de modernidad alternativa a la actual crisis civilizatoria. 2. El espacio local de referencia: la Sierra de Santa Marta (Veracruz, México). 2.1. Caracterización general de la Sierra de Santa Marta. 3. Algunos conceptos, teorías y modelos emergentes para contextualizar los procesos alternativos al desarrollo en la Sierra de Santa Marta. 3.1. Algunos posibles modelos emergentes alternativos al desarrollo. 3.2. Otras formas de relación económica no orientadas por la lógica de mercado. 4. Metodología de la investigación. 5. Prácticas socioespaciales alternativas para la sustentabilidad en la Sierra de Santa Marta. 5.1. Experiencias emergentes de gestión integral, sustentable e intercultural de recursos naturales. 6. Resistencias indígenas interculturales frente al poder del modelo desarrollista hegemónico capitalista. 6.1. Gestión integral de recursos naturales con enfoque holístico: la cuenca hidrográfica. 6.2. Primeros intentos de cooptación de las iniciativas alternativas interculturales por las lógicas desarrollistas neoliberales hegemónicas. Conclusiones. Bibliografía.

\section{Introducción: imaginación socioespacial y reconstrucción de la economía frente a la crisis del desarrollo}

\subsection{La necesaria reconstrucción de la economía convencional}

Los sistemas económicos son sistemas abiertos, es decir, "forman parte de un sistema político e institucional más amplio que, a su vez, está ineludiblemente relacionado con el sistema ecológico" (Kapp, 1978: 128). Asimismo, "la organización de sistemas económicos guiados por valores de intercambio, es incompatible con los requerimientos de los sistemas ecológicos y la satisfacción de las necesidades humanas básicas" (Kapp, 1978: 132). Por ello, resulta evidente que, ante la multiplicidad de interdependencias económicas y ecológicas en el sistema globalregional-local, la reconstrucción de la economía convencional parece sencillamente ineludible.

Por otra parte, unos años antes del discurso del presidente Truman (1949) ${ }^{1}$, Polanyi publicó La gran transformación. Crítica del liberalismo económico (1944). Este autor estaba convencido de que el determinismo económico era un fenómeno

\footnotetext{
${ }^{1}$ La crítica del desarrollo ha establecido una clara distinción entre los usos previos de la palabra desarrollo y el que adquirió a partir del 20 de enero 1949, cuando Harry Truman, el día de su toma de posesión como presidente de los Estados Unidos de América, acuñó políticamente el término "subdesarrollo". Desde entonces se modificó la denotación y connotaciones de la expresión, para asociarla únicamente con el experimento de la posguerra, surgido de un ejercicio hegemónico norteamericano. Sin embargo, a partir de los años 70, las expectativas de un progreso acumulativo, ilimitado y universal implícitas en el antidemocrático paradigma y/o discurso desarrollista (basado en el concepto de "trato justo" de Truman y de la coyuntura histórica específica de finales de la Segunda Guerra Mundial) comienzan a resquebrajarse: "Hay un sentido en el que el progreso económico acelerado es imposible sin ajustes dolorosos. Las filosofías ancestrales deben ser erradicadas; las viejas instituciones sociales tienen que desintegrarse; los lazos de casta, credo y raza deben romperse; y grandes masas de personas incapaces de seguir el ritmo del progreso deberán ver frustradas sus expectativas de una vida cómoda. Muy pocas comunidades están dispuestas a pagar el precio del progreso económico" (United Nations, 1951: 15).
} 
del siglo XIX, de que el sistema de mercado distorsionaba violentamente nuestra visión sobre el ser humano y la sociedad, y de que tales distorsiones se estaban mostrando como uno de los principales obstáculos para la solución de los problemas de nuestra civilización. Conjuntamente, Polanyi documentó cuidadosamente la historia económica occidental como la historia de la creación de la economía en tanto que esfera autónoma, separada del resto de la sociedad.

En su discurso de posesión como presidente de los Estados Unidos el 20 de enero de 1949, Truman anunció al mundo entero su concepto de "trato justo". Un componente esencial del concepto era su llamamiento a los Estados Unidos y al mundo para resolver los problemas de las "áreas subdesarrolladas" del globo ${ }^{2}$ :

Más de la mitad de la población del mundo vive en condiciones cercanas a la miseria. Su alimentación es inadecuada, es víctima de la enfermedad. Su vida económica es primitiva y está estancada. Su pobreza constituye un obstáculo y una amenaza tanto para ellos como para las áreas más prósperas. Por primera vez en la historia, la humanidad posee el conocimiento y la capacidad para aliviar el sufrimiento de estas gentes [...] Creo que deberíamos poner a disposición de los amantes de la paz los beneficios de nuestro acervo de conocimiento técnico para ayudarlos a lograr sus aspiraciones de una vida mejor [...] Lo que tenemos en mente es un programa de desarrollo basado en los conceptos del trato justo y democrático [...] Producir más es la clave para la paz y la prosperidad. Y la clave para producir más es una aplicación mayor y más vigorosa del conocimiento técnico y científico moderno (Truman, 1964 citado en Escobar, 1998: 19).

Retomando a Polanyi (1944), quien puso los cimientos de la historia económica comparativa, se puede afirmar que las leyes económicas de los economistas clásicos no eran más que invenciones deductivas que transformaron los nuevos modelos observables de conducta social; modelos que se habían adoptado con el nacimiento de la sociedad económica en axiomas universales destinados a llevar adelante un nuevo proyecto político. Además, la presunción de la existencia previa de leyes o hechos económicos, interpretados e interpretables por los economistas, no se sostiene cuando la confrontamos con lo que disciplinas como la antropología social y cultural muestran acerca del funcionamiento socioeconómico en las sociedades y culturas originarias. Al respecto, entre otros autores, Sahlins (1972) y Clastres

\footnotetext{
${ }^{2}$ La doctrina Truman inició una nueva era en la comprensión y el manejo de los asuntos mundiales, en particular de aquellos que se referían a los países económicamente menos avanzados. El propósito, bastante ambicioso, era crear las condiciones necesarias para reproducir en todo el mundo los rasgos característicos de las sociedades avanzadas de la época: altos niveles de industrialización y urbanización, tecnificación de la agricultura, rápido crecimiento de la producción material y los niveles de vida, y adopción generalizada de la educación y los valores culturales modernos.
} 
(1974) han descrito documentadamente y con exhaustivo detalle culturas en las que presupuestos no económicos gobiernan las vidas de los seres humanos.

\subsection{La nueva lógica de los márgenes del sistema y las culturas substantivas invisi- bilizadas por la meta del discurso desarrollista}

Lo anterior converge en buena medida con lo que Esteva (2004: pássim) identifica con la situación propia de los llamados "marginales"; es decir, esos hombres y mujeres que viven, o se considera que viven, en los márgenes del mundo económico y que continúan desafiando los presupuestos económicos, tanto en la teoría como en la práctica, si bien no encajan con ninguna de las clasificaciones sociales filtradas a través de las lentes de los economistas.

Para el ser humano corriente que habita los márgenes de la esfera económica, luchar para limitarla no es una reacción mecánica a la invasión económica de sus vidas y ven su resistencia como una reconstitución creativa de formas básicas de interacción social, cuyo propósito último es liberarlos de las cadenas económicas. Ello no quiere decir que las gentes que ocupan estos espacios nuevos no sean los herederos, que lo son, de una colección diversificada de comunes, de comunidades e, incluso, de culturas enteras que resultaron destruidas por la forma de interacción social, económica, industrial. Tras la extinción de sus regímenes de subsistencia, probaron distintos sistemas de acomodo a la forma industrial.

Sin embargo, ni la sociedad industrial por sí misma, ni los remanentes de las formas tradicionales que trataron de adaptarse a ella, pudieron culminar con éxito el mencionado proceso de acomodo. Este fracaso es la condición previa de las invenciones sociales, cuya consolidación y florecimiento han sido todavía más estimulados por la llamada crisis del desarrollo.

En abierto contraste, las gentes de los "márgenes" se ven forzadas a confinar su interacción económica, para algunos muy frecuente e intensa, en dominios externos a los espacios en los que organizan sus modos de vida propios. Estos espacios eran su último refugio durante la era del desarrollo. Tras experimentar lo que significa la supervivencia en una sociedad económica, hoy están recontando las bendiciones que hallaron en dichos refugios, a la vez que trabajan activamente para regenerarlos.

Apoyándose en experiencias recientes, la nueva conciencia y lógica que emerge de los márgenes puede despertar otras, ampliando las mencionadas coaliciones hacia el punto crítico en el que empiece a ser factible la inversión más allá de la dominación de la economía de mercado capitalista en todas las esferas de la vida del ser humano. De este modo, estas nuevas prácticas socioeconómicas están dando pruebas de la capacidad de la gente común en espacios locales para reaccionar con imaginación socioespacial ante entornos estructurales globales hostiles. Así, en diferentes lugares del mundo, caso de la Sierra de Santa Marta (Veracruz, México), se están poniendo en marcha acontecimientos poseconómicos con el propósito de 
limitar el daño económico del capitalismo y hacer sitio a las nuevas formas de vida social.

La emergencia de estos nuevos acontecimientos poseconómicos es en gran medida posible gracias al florecimiento de iniciativas poseconómicas sustentadas en proyectos político-morales antes que económicos, y que se definen como otras economías: "alternativas" (Santos, 2004), "sociales" y "solidarias" (Laville, 2000; Lipietz, 2002), "antiutilitaristas" (Caillé, 1996), "postdesarrollistas" (Gibson y Graham, 2006), "del trabajo” (Coraggio, 2004), etc.

\subsection{Geometría del poder y nuevas geografías de la responsabilidad}

Por otro lado, el concepto de "geometría del poder"3, propuesto por Massey, pretende transmitir un sentido de la complejidad de las relaciones entre espacio, lugar y escala. Esta noción geopolítica implica un tipo de pensamiento relacional que pone énfasis en tres aspectos:

1) siempre existe la necesidad de pensar los lugares y las comunidades dentro de relaciones y formas de poder que se extienden más allá de lo local;

2) los lugares son siempre los sitios de negociación y de continua transformación y,

3) cualquier noción relacional de espacio y lugar exige una política de la responsabilidad hacia aquellas conexiones que dan forma a nuestras vidas y lugares, lo que la misma Massey (2004) llama "geografías de la responsabilidad".

Estas geografías, que surgen de la relacionalidad, están conectadas con la cultura, la subjetividad, la diferencia y la naturaleza. Esto quiere decir que las nuevas geometrías del poder deben afrontar directamente nuestro encerramiento ecológico y cultural.

Por su parte, la sociedad liberal resuelve la cuestión de la responsabilidad de un modo que ya no funciona; así, extendidas en todas direcciones y por todo tipo de procesos, desde la migración hasta la destrucción ambiental, la espacialidad liberal

\footnotetext{
${ }^{3}$ Doreen Massey plantea el concepto de "geometría del poder" basado en sus experiencias e ideas asociadas a Londres y sus relaciones geográficas con el resto de ciudades del Reino Unido. Relaciones que iban más allá de lo netamente demográfico, comercial o cultural. Relaciones que involucraban la distribución desigual del poder con inmediatas consecuencias en la perpetuación de la inequidad social. En sus palabras "el poder siempre tiene una geografía". La geometría del poder explica las desigualdades sociales generadas por la economía capitalista - perspectiva claramente marxista - creando una rígida brecha entre ricos y pobres y entre clases sociales. Massey argumentó la importancia del lugar y la posición que se ocupa, frente a las concepciones estáticas del término.
} 
y la política de responsabilidad de la modernidad podrían estar "desplomándose" (Escobar, 2010: 74).

\subsection{Las iniciativas poseconómicas: propuestas posibles de modernidad alternativa a la actual crisis civilizatoria}

Por otro lado, como resultado de un enorme esfuerzo de crítica y de búsqueda de alternativas a la actual crisis civilizatoria y de producción de un conocimiento definido por la utilidad social, un nuevo paradigma ecológico ha emergido frente a la visión del mundo que ha sustentado la modernidad. Y es que la precaria situación actual de los pueblos indígenas campesinos, tanto ecológica como demográfica y socioeconómica, exige soluciones inmediatas en cuya búsqueda las ciencias sociales deben cooperar ineludiblemente.

Así, a tenor de todo lo anterior, en este artículo con base en cuestiones multi y transdisciplinares (geográficas, ecológicas, históricas, demográficas, económicas, sociales, geopolíticas, culturales, etc.) se ofrece una propuesta posible de modernidad alternativa a partir de la identificación, análisis y etnografía de diversas experiencias de gestión alternativa posible de recursos naturales y transformaciones socioespaciales poseconómicas en el espacio regional de la Sierra de Santa Marta en Veracruz (México).

\section{El espacio local de referencia: la Sierra de Santa Marta (Veracruz, México)}

\subsection{Caracterización general de la Sierra de Santa Marta}

La Sierra de Santa Marta es uno de los dos macizos volcánicos que conforman la región geográfica, histórica y cultural de Los Tuxtlas (Mapa 1), en el sureste del estado mexicano de Veracruz. Ambos macizos están separados por una depresión en la que se encuentran el Lago de Catemaco y la Laguna de Sontecomapan. El macizo sureste que corresponde a la Sierra de Santa Marta o de Soteapan lo integran los volcanes de San Martín Pajapan (1.270 msnm) y Santa Marta (1.550 $\mathrm{msnm}$ ), situados sobre el litoral veracruzano y limitando con el Golfo de México al noroeste y con la Laguna del Ostión al sureste (Mapa 1).

Las 150.000 hectáreas del territorio de la Sierra de Santa Marta (Mapa 1) corresponden a seis municipios en los que predomina la población de autoadscripción indígena nahua y popoluca (Cuadro 1). En esta región, como lo atestiguan diversos vestigios arqueológicos, se asentaron grupos olmecas y posteriormente zoquepopolucas y nahuas, descendientes directos de la cultura olmeca con influencias de las culturas teotihuacana, totonaca y maya. Estos pobladores originarios "supieron adaptarse a las condiciones de la selva tropical para practicar la agricultura y apro- 
vechar los recursos que les ofrecían las selvas y bosques de la montaña" (Blom y Lafarge, 1926: 33).

Mapa 1. Localización geográfica de la Sierra de Santa Marta en el estado de Veracruz (México) dentro de su entorno de referencia, la región de Los Tuxtlas y el sureste del litoral veracruzano del Golfo de México

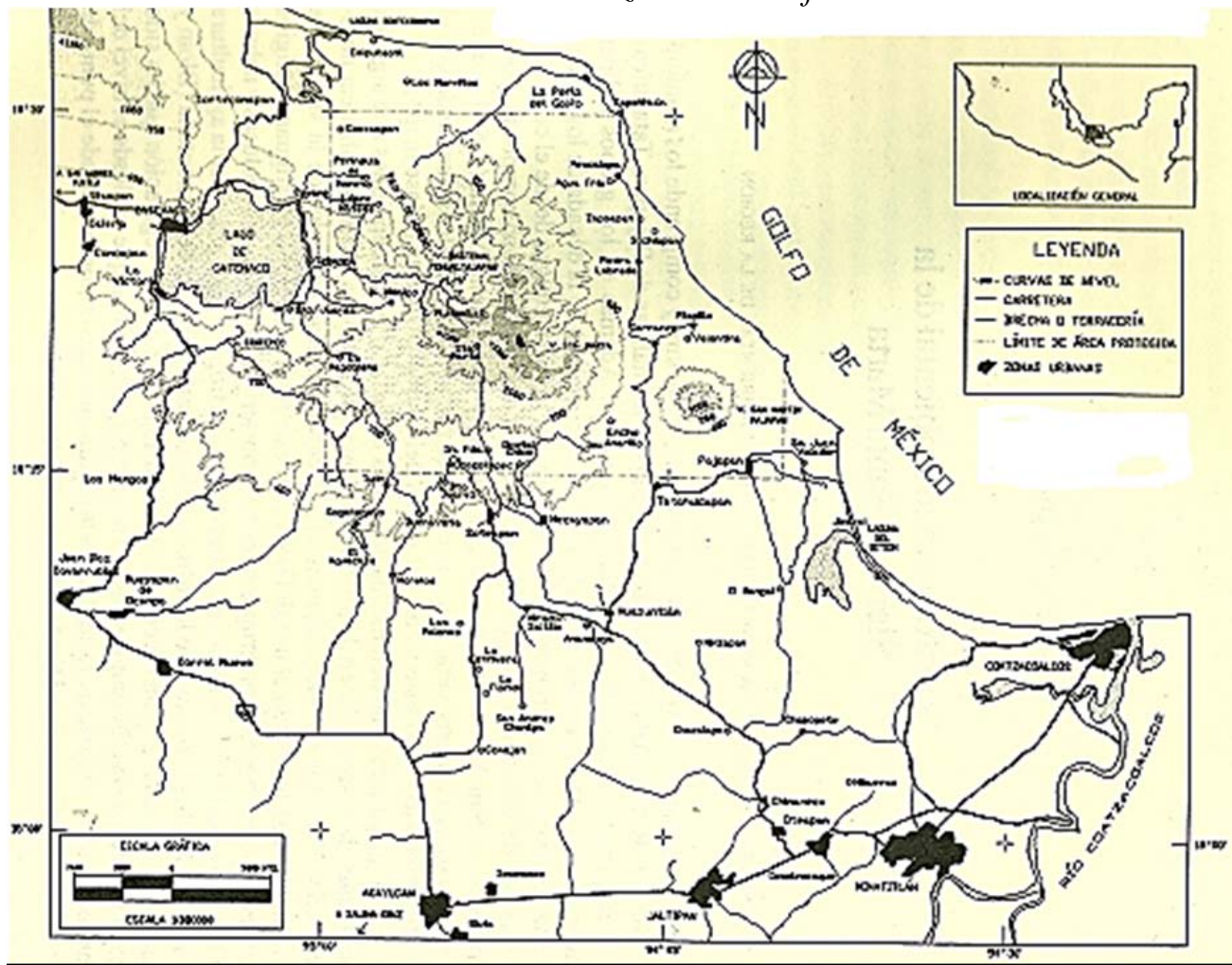

Fuente: mapa elaborado por Fernando Ramírez (PSSM) y Martha Patricia Lozada (PSSM) a partir de las Cartas (INEGI, 1982) con verificación de campo.

Una gran diversidad de ecosistemas y tipos de vegetación, así como un rango altitudinal que va desde el nivel del mar hasta los $1.550 \mathrm{msnm}$, le confieren a la región un rango importante desde el punto de vista de la biodiversidad. Sin embargo, no se han tomado todas las medidas oficiales que serían necesarias para detener la constante destrucción de las zonas forestales, la degradación de los suelos y un aprovechamiento no sustentable de los recursos naturales.

Es más, durante las últimas décadas ha prevalecido un proceso denominado "subdesarrollo sostenido" (Chevalier y Buckles, 1995: 126). Esta noción ha sido producto de las políticas económicas gubernamentales para la región que han acele- 
rado este proceso, básicamente mediante el apoyo a programas de desarrollo ganadero y a programas asistencialistas y paternalistas que dependen de insumos externos.

Cuadro 1. Población de la Sierra de Santa Marta de autoadscripción indígena (2010)

\begin{tabular}{|l|c|c|c|}
\hline \multicolumn{1}{|c|}{ Municipio } & $\begin{array}{c}\text { Población total } \\
\text { (miles habitantes) }\end{array}$ & $\begin{array}{c}\text { Población indígena } \\
\text { (miles habitantes) }\end{array}$ & $\begin{array}{c}\text { Población indígena } \\
\text { sobre total (\%) }\end{array}$ \\
\hline Catemaco & 45.383 & 39.868 & 87,84 \\
\hline Hueyapan de Ocampo & 39.795 & 34.902 & 87,70 \\
\hline Mecayapan & 15.210 & 13.046 & 85,77 \\
\hline Pajapan & 14.071 & 12.239 & 86,98 \\
\hline Soteapan & 27.486 & 23.143 & 84,19 \\
\hline Tatahuicapan de Juárez & 12.488 & 10.518 & 84,22 \\
\hline TOTAL & $\mathbf{1 5 4 . 4 3 3}$ & $\mathbf{1 3 3 . 7 1 6}$ & $\mathbf{8 6 , 5 8}$ \\
\hline
\end{tabular}

Fuente: Elaboración propia a partir de datos tomados del Censo de Población y Vivienda, 2010 (INEGI).

De esta forma, actualmente existe un modelo de producción primaria que se ha caracterizado por la sobreexplotación de algunos recursos sin ningún tipo de plan de regeneración de los mismos y, en otros casos, por la subutilización de las posibilidades de producción en un medio rural rico en recursos endógenos, pero pobre en el manejo que de ellos se hace.

Los resultados más dramáticos de estos procesos han sido la destrucción de 51.770 ha de selva entre 1967 y 1992 (Mapa 2) y la pérdida de la tradicional autosuficiencia alimentaria a causa del brusco descenso de la producción maicera (Cuadro 2).

Mapa 2. Proceso de deforestación en la región de Los Tuxtlas y la Sierra de Santa Marta en 1967, 1976, 1986 y 1992 (de izquierda a derecha)

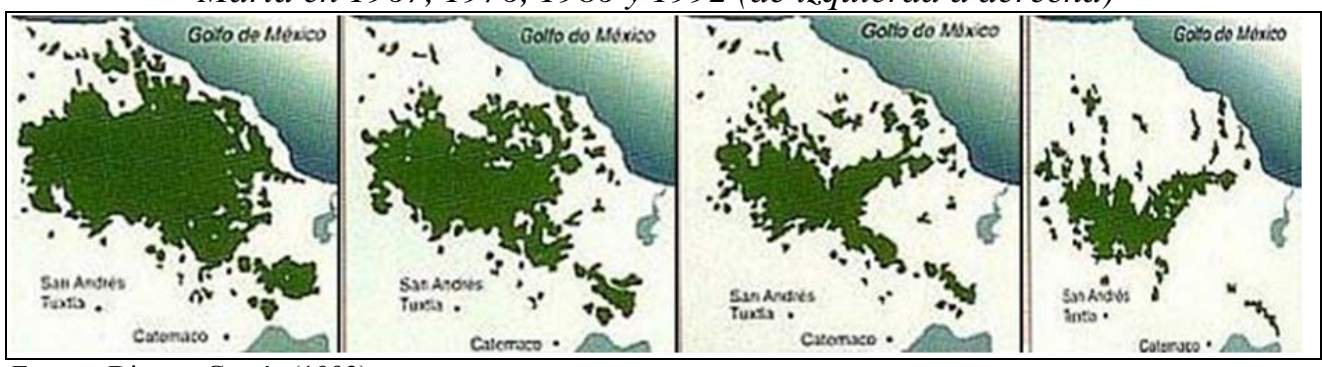

Fuente: Dirzo y García (1992).

Bajo el modelo global de políticas desarrollistas, a semejanza del patrón regional de cambio en los usos del suelo del trópico húmedo mesoamericano, a escala local 
en la Sierra de Santa Marta opera desde 1950 un tipo de desarrollo que se caracteriza por la promoción de las actividades ganaderas y la dotación de tierras para la formación de ejidos.

Cuadro 2. Evolución de la superficie cultivada de maíz en el municipio de Pajapan (1950-1999)

\begin{tabular}{|l|c|c|c|c|c|}
\hline Municipio & $1950(\mathrm{ha})$ & $1960(\mathrm{ha})$ & $1970(\mathrm{ha})$ & $1985(\mathrm{ha})$ & $1999(\mathrm{ha})$ \\
\hline Pajapan & 6.668 & 5.566 & 6.690 & 1.305 & 2.720 \\
\hline
\end{tabular}

Fuente: Censos Agropecuarios de 1950, 1960, 1970, 1981, 1991 y 2001 (INEGI).

En conjunto, estas políticas públicas de fomento de actividades poco compatibles con la preservación de los recursos naturales han propiciado la eliminación masiva de la vegetación forestal en tierras privadas y la "tala hormiga" en los terrenos de propiedad colectiva. Según Paré y Lazos, actualmente quedan solamente "26.000 hectáreas cubiertas de vegetación de manera continua y unas 12.000 hectáreas más en manchones dispersos" (2000: 35) (Mapa 2). Estas selvas actualmente se encuentran cobijadas a modo de reliquias en las cimas volcánicas más abruptas de las montañas.

En cuanto a los procesos demográficos más notables en la región, destacan el crecimiento demográfico sostenido y la densificación de la población, que ya están provocando graves afecciones relacionadas con la sobrepoblación. Para el año 2005, los municipios de la Sierra de Santa Marta son los que presentaron las más altas tasas de crecimiento en la región, con una tasa promedio de $1,21 \%{ }^{5}$, mientras que la tasa promedio regional fue de $1,08 \%$ (elaboración propia).

Por ello, la emigración es un fenómeno que recientemente se intensifica y tiende a ser muy importante. Conforme a la CONANP-SEMARNAT (2006: 52), hacia el último quinquenio de la década de los noventa, como producto de la cancelación de miles de empleos en las urbes próximas (más de 60.000 trabajadores desempleados en el sur del estado de Veracruz), fruto de la crisis que afectó al sector industrial

\footnotetext{
${ }^{4}$ La extracción irregular y clandestina de madera o "tala hormiga" afecta a la actividad forestal que se realiza de manera regular y ordenada, pues se considera que genera competencia desleal con los productores forestales organizados al producir productos a menor costo, y se le señala como el principal factor que atenta contra la permanencia del bosque. La deforestación producida por la tala hormiga es un fenómeno difícil de erradicar porque está asociada a la pobreza y a la marginación en que viven cientos de comunidades campesinas asentadas en las regiones de las montañas veracruzanas. La explotación de madera tipo "hormiga" es la tala selectiva de los pocos árboles de cedro, primavera, laurel, suchil, bari, etc., que aún existen en las selvas y bosques de la Sierra de Santa Marta. Estos árboles son derribados y cortados en tabla en el monte, usando generalmente motosierras. Son trasladados con bestias de carga a los centros de población o a los lugares donde se puede comercializar.

${ }^{5}$ Instituto Nacional de Estadística y Geografía (INEGI). Información documental y estadística disponible en línea. [URL: <http://www.inegi.org.mx/>. Consultado el 24 de marzo de 2014].
} 
petroquímico del sureste veracruzano, se registró un proceso de retorno de varios miles de habitantes hacia la Sierra de Santa Marta.

Además, en los últimos lustros se han cerrado las tres más importantes válvulas de escape que permitían cubrir el déficit de tierras y alimentos. Estas salidas eran: la migración a las ciudades del corredor industrial petroquímico JáltipanCoatzacoalcos (Mapa 1), el cultivo y comercialización del café, y el uso comunal de tierras ejidales.

Actualmente, el desempleo en las diferentes industrias petroquímicas del Sur de Veracruz continúa provocando un retorno masivo al campo, donde la situación tampoco es favorable (precio ínfimo del café en el mercado internacional, baja productividad del maíz, carencia de apoyos para desarrollar otros cultivos o actividades económicas, etc.). La ganadería tampoco está en su mejor momento, pues se ha tenido que vender el ganado vacuno a precios menores de lo que se compró, provocando un desesperante problema de carteras vencidas entre los ganaderos.

Por todo lo anterior, un fenómeno reciente del cual aún no existe un conocimiento cuantitativo preciso es el de los procesos de emigración o migración-expulsión hacia los estados del norte de México (Baja California, Chihuahua, Sinaloa o Sonora) o hasta los Estados Unidos ${ }^{6}$. En los núcleos urbanos de la Sierra de Santa Marta se han instalado oficinas reclutadoras de migrantes que ofrecen empleos en diferentes lugares. Aunque no existen datos concretos, diversos testimonios de informantes locales indican que al menos un autobús parte cada semana con gente de la región, jóvenes en su gran mayoría, en busca de mejores oportunidades laborales.

Este fenómeno migratorio local debe de observarse en el contexto de la situación nacional, dado que actualmente Veracruz es uno de los estados con mayor expulsión rural, ocupando el cuarto lugar después de Oaxaca, Guerrero y Zacatecas. Así, en estos primeros albores del siglo XXI muchos jóvenes y adultos, de ambos géneros, se ven obligados a tomar el camino de la emigración masiva como mano de obra barata hacia lugares ubicados a más de $1.000 \mathrm{~km}$ de sus comunidades de origen. Movimientos migratorios que, dependiendo de su escala geográfica, en mayor o menor medida conllevan una compleja problemática para los migrantes y sus familias tanto en los lugares de partida como de llegada.

El principal destino de estos jóvenes indígenas campesinos es bien emplearse como obreros poco cualificados en la industria maquiladora de exportación de las ciudades fronterizas del norte de México como Ciudad Juárez o Tijuana, bien ser contratados por las agroindustrias dedicadas a la producción de hortalizas de invierno para el mercado norteamericano en los estados de Baja California, Chihuahua o Sinaloa. También en muchos casos se verán obligados a la migración transnacional hacia los Estados Unidos y Canadá.

\footnotetext{
${ }^{6}$ Para un desarrollo más detallado de este fenómeno migratorio véase Velázquez (2013).
} 
Según cálculos propios, dentro de los límites de la Sierra viven actualmente 154.433 habitantes, lo que arroja una relación población/territorio de $49,3 \mathrm{hab} . / \mathrm{km}^{2}$. Estos guarismos hablan claramente de la intensa presión ejercida sobre los recursos naturales locales. Ello también ofrece una idea aproximada del enorme reto que conlleva armonizar los objetivos de protección y conservación de los recursos naturales endógenos con los de procurar el bienestar de una población indígena campesina históricamente muy marginada, y que de forma acuciante requiere satisfacer amplias demandas de primera necesidad.

Así, a la terrible pérdida de recursos forestales por la tala ilegal de la selva para la siembra de pastos para la ganadería extensiva promocionada desde las políticas públicas, se suma la pobreza y vulnerabilidad de la mayoría de los productores agrícolas y ganaderos de la Sierra de Santa Marta. Éstos, además, tras la retirada de los programas asistenciales carecen de alternativas técnicas, de créditos y de mercados para reconvertir sus actividades pecuarias a agrícolas o forestales, o para pasar de una ganadería extensiva a otro de tipo intensivo.

Todo lo anterior conduce a alertar sobre la urgencia de buscar modelos alternativos de desarrollo (Moreno-Arriba, 2014) para contribuir a la mejora de la precaria situación actual, tanto ecológica como demográfica y socioeconómica, de las comunidades indígenas campesinas que ancestralmente habitan el sureste veracruzano. No obstante, como se cuestiona Velázquez: “¿cómo podrían crearse estas alternativas en un contexto de reducción al mínimo de la inversión pública para el campo y de inserción desventajosa en el mercado internacional?" (2000: 123).

Mientras tanto, el grupo de ambientalistas que opera en la región de Los Tuxtlas desde 1990, vinculado al Proyecto Sierra de Santa Marta A. C (PSSM), comenzará a conseguir apoyos financieros de diversas agencias, embajadas y grupos internacionales no gubernamentales y/o civiles. Estos financiamientos, luego que desde el discurso ambientalista la ganadería bovina extensiva ha sido cuestionada abiertamente, han estado destinados a actividades socioespaciales alternativas como el impulso de las actividades productivas integrales y sustentables a través de proyectos, programas e iniciativas interculturales de conservación de suelos, reforestación, restauración hídrica, fomento de los modelos agrosilvopastoriles, manejo dendroenergético, promoción de cultivos para la producción de recursos forestales no maderables, transformación de bienes maderables en productos artesanos, plantación de frutales, manejo sostenible de los recursos pesqueros lacustres, prácticas de ecoturismo, etc.

\section{Algunos conceptos, teorías y modelos emergentes para contextualizar los procesos alternativos al desarrollo en la Sierra de Santa Marta}

Durante la segunda mitad del siglo XX dentro del ámbito del desarrollo se ha producido varios cambios notables: 
1) un devastador efecto provocado por el reduccionismo conceptual y metodológico que ha ido imponiéndose en ciertos ámbitos académicos para afrontar el análisis de fenómenos mucho más complejos que en épocas anteriores;

2) unas manifiestas muestras de limitación teórica y metodológica del llamado pensamiento oficial sobre el desarrollo a la hora de interiorizar y cambiar el discurso en torno a algunos de los retos más importantes que en la actualidad condicionan el bienestar de los seres humanos y la proyección del mismo hacia las futuras generaciones; $y$

3) en los últimos años, al socaire de un conjunto de posicionamientos críticos que cuestionan abiertamente la capacidad del crecimiento económico para superar el "subdesarrollo" y generar "desarrollo", entendido éste como un incremento en el bienestar de las personas, se han ido abriendo paso distintos enfoques que cuestionan ideas y conceptos impuestos por la concepción desarrollista surgida como una fuerza hegemónica tras la Segunda Guerra Mundial.

En esta coyuntura, en la literatura vienen surgiendo conceptos, teorías y modelos que crean una atmósfera de respaldo a los modelos alternativos al desarrollo. Entre ellos se encuentran el "etnodesarrollo" (Bonfil, 1982), la "participación" (Rahnema y Bawtree, 1996), el "empoderamiento" (de género), el "diálogo de saberes" y la "colaboración intercultural". Estas nociones frecuentemente han sido manipuladas en el entorno de agencias, organismos multilaterales y desde el centro neurálgico de la industria del desarrollo, el Banco Mundial. A partir de los conceptos y teorías anteriores surgen y se construyen los postulados del pensamiento y las prácticas de modelos emergentes que pueden ser considerados como alternativas al arquetipo convencional desarrollista, como entre otros son la interculturalidad, la ecología política, la agroecología o la sustentabilidad integral ${ }^{8}$ asumida en este artículo.

La construcción de determinados espacios de acción en torno a estos modelos teóricos emergentes, junto a otras formas de relación económica no orientadas por la lógica de mercado (lógica de la acumulación) sino por una lógica de la vida (lógica de la reproducción), también adoptadas en este artículo, facilitan proyectos diversos de intervención a partir de iniciativas autodenominadas "alternativas"

\footnotetext{
${ }^{7}$ Esto ha sido denominado por algunos como "maldesarrollo" (Amin, 1990; Slim, 1998; Tortosa, 2001).

${ }^{8}$ En este trabajo de investigación se asume por sustentabilidad integral: "Un compromiso efectivo de contribuir a la conformación de una nueva etapa civilizatoria, basada en el conocimiento, que armonice la vida de los seres humanos consigo mismos y entre sí, que promueva el desarrollo socioeconómico con equidad y practique una actitud respetuosa del medio ambiente para conservar en el largo plazo la vitalidad y diversidad de nuestro planeta [...] como un conjunto de relaciones entre sistemas (naturales y sociales), dinámica de procesos (energía, materia e información) y escalas de valores (ideas, ética, etc.)” (Jiménez, 2000: 109).
} 
(Narotzky, 2010: 127). Estas y otras ideas son las que aquí se tratan de dotar de contenido empírico a través de la etnografía del discurso y las prácticas de los actores protagónicos de esta investigación.

\subsection{Algunos posibles modelos emergentes alternativos al desarrollo}

Partiendo de la constatación de que una de las principales causas del fracaso de tantos y tantos proyectos de desarrollo en aquellos países que según su índice de desarrollo humano (IDH) ${ }^{9}$ son considerados como "subdesarrollados" y en "vías de desarrollo" fue su escasa adecuación al marco cultural de las poblaciones destinatarias, surge la propuesta alternativa del etnodesarrollo, entendiendo por tal: "El ejercicio de la capacidad social de un pueblo para construir su futuro, aprovechando para ello las enseñanzas de su experiencia histórica y recursos reales y potenciales de su cultura, de acuerdo con un proyecto que se defina según sus propios valores y aspiraciones" (Bonfil, 1982: 133).

Por otro lado, desde el enfoque del desarrollo participativo, Rahnema y Bawtree (1996) perciben la participación como un instrumento de mayor eficacia, así como una nueva fuente de inversión: los procesos participativos suministran a los proyectos de desarrollo lo que más necesitan para evitar las trampas y fracasos del pasado, a saber:

a) un conocimiento cercano de las realidades en el terreno con el que no cuentan los técnicos extranjeros y los burócratas estatales;

b) redes de relaciones que son esenciales tanto para el éxito de los proyectos en curso como para las inversiones a largo plazo en las áreas rurales; y

c) la cooperación a nivel local de organizaciones capaces de llevar a cabo las actividades de desarrollo.

\footnotetext{
${ }^{9}$ El índice de desarrollo humano (IDH) es un indicador del desarrollo humano por país elaborado por el Programa de las Naciones Unidas para el Desarrollo (PNUD). Se basa en un indicador social estadístico compuesto por tres parámetros: Salud (vida larga y saludable, medida según la esperanza de vida al nacer); Educación (medida por la tasa de alfabetización de adultos y la tasa bruta combinada de matriculación en educación primaria, secundaria y superior, así como los años de duración de la educación obligatoria) y Riqueza (nivel de vida digno, medido por el PIB per cápita en dólares internacionales). Este indicador surge del Informe sobre Desarrollo Humano iniciado en 1990 por el PNUD, un informe independiente resultado del trabajo de un equipo de académicos destacados. En gran parte, se basa en las ideas desarrolladas por el filósofo y economista bengalí Amartya Sen, teórico de la economía del desarrollo que fue galardonado con el Premio Nobel de Economía en 1998. El IDH distingue entre países desarrollados, países en desarrollo y países subdesarrollados.
} 
Por su parte, el enfoque del empoderamiento, con énfasis especial en el de género, está relacionado con el acceso y control de tres tipos de poderes: a) el social, entendido como el acceso a la base de riqueza productiva; b) el político, o acceso de los individuos al proceso de toma de decisiones, sobre todo aquellas que afectan a su propio futuro; y c) el psicológico, entendido en el sentido de potencialidad y capacidad individual (Friedman, 1992: 33).

Conjuntamente, como describe Haraway (1995: pássim), la posmodernidad está marcada por el fin de los universalismos y los esencialismos; por la emergencia de entes híbridos hechos de organismo, símbolos y tecnología; por la imbricación de lo tradicional y lo moderno.

Por consiguiente, el problema a resolver por enfoques y modelos emergentes de desarrollo con visiones críticas, transformadoras y globales, que vinculan permanentemente los aspectos ecológicos y sociales, no es sólo el dejar atrás el esencialismo de la ontología occidental, sino el principio de universalidad de la ciencia moderna. Para ello resulta ineludible un cuestionamiento de la ciencia, de la colonialidad del conocimiento científico y, en general, de toda episteme occidental. Semejante actitud lleva a diversos autores a abogar por una suerte de diálogo de saberes: "Se trata, a fin de cuentas, de interrelacionar y con ello de descolonizar diversos saberes legos, populares, tradicionales, urbanos, campesinos, provincianos, de culturas no occidentales (indígenas, de origen africano, oriental, etc.) que circulan en la sociedad" (Santos, 2005: 69).

En este contexto asimétrico, en los últimos años se ha desarrollado una propuesta conceptual y metodológica recurriendo a las nociones de diálogo de saberes y diálogo intercultural. Se parte de la colonialidad del saber y del desafío de generar cauces innovadores para diversificar dicho conocimiento, para relacionarlo con conocimientos indígenas, locales, etnociencias subalternas y saberes alternativos, que en su confluencia pueden y deben hibridizarse y fertilizarse mutuamente, construyendo así nuevos cánones diversificados, enredados y glocalizados de conocimiento (Mignolo, 2005; Walsh et al., 2003; Escobar, 2007).

En consecuencia, la propuesta teórica y metodológica alternativa pretende lograr una "construcción intercultural del saber" (García Canclini, 2004: pássim), que se basa en la larga tradición latinoamericana de colaboración estrecha entre movimientos sociales y grupos de base, por un lado, e intelectuales y académicos activistas, por otro lado. Este tipo de práctica socioeducativa puede ser aprovechada para una novedosa "colaboración intercultural en la producción de saberes y conocimientos" (Mato, 2008: pássim).

Entre los diferentes tipos y formas de conocimientos se propone por tanto un "diálogo de saberes" (Leff, 2003; Santos, 2007; Argueta, 2011; Toledo, 2011, entre otros). No obstante, la metáfora del diálogo no logra ocultar ni el carácter asimétrico de dicho acto comunicativo ni la conflictividad inherente a tal puesta en diálogo.

Como enfatiza uno de los promotores de este tipo de diálogo, los saberes pueden ser complementarios en la práctica campesina cotidiana, pero a menudo no son 
fácilmente subsumibles o incorporables al saber canónico, al conocimiento científico:

El saber (ambiental), con su criticidad de la razón dominadora, no es internalizable en los paradigmas científicos y no se disuelve su diversidad y diferencia en la totalidad del conocimiento objetivo ni en el saber de fondo que posibilita un consenso de saberes a través de una racionalidad comunicativa. Este "Otro" del conocimiento no se deja tematizar ni sistematizar; su "concepto" se retrae de todo afán de concreción y objetividad (Leff, 2003: 22).

Por su parte, Boaventura de Sousa Santos reclama la necesidad de ampliar los llamados diálogos interculturales, a menudo limitados de forma esencializante a intercambios epistémicos entre "representantes" de determinadas culturas, religiones o civilizaciones, hacia una "ecología de saberes" (Santos, 2006). Esta mirada más integral y ecológica incluiría todo el "conjunto de prácticas que promueven una nueva convivencia activa de saberes con el supuesto de que todos ellos, incluido el saber científico, se pueden enriquecer en este diálogo" (Santos, 2005: 70).

\subsection{Otras formas de relación económica no orientadas por la lógica de mercado}

A su vez, dentro de las ciencias sociales, teóricos como Caillé (1996), Laville (2000), Santos (2004) y Gibson y Graham (2006) recuperan el concepto de reciprocidad y de don para subrayar la existencia de otras formas de relación económica no orientadas por la lógica de mercado (lógica de la acumulación) sino por una lógica de la vida (lógica de la reproducción). En esta filiación, el proyecto político de estos científicos sociales, como uno de los propósitos de este texto, es re-moralizar la economía, devolverle su independencia respecto a objetivos humanos fundamentalmente ligados a la reproducción de vida. En cualquier caso, como advierte Narotzky (2010: 128-129), el don, la reciprocidad y la base son proyectos políticomorales antes que económicos, y se definen como otras economías.

Retomando diversos postulados de autores postdesarrollistas como Escobar (2010: 44-46), se puede aseverar que las actuales transformaciones políticas, sociales y culturales sugieren la existencia de dos proyectos potencialmente complementarios:

a) modernizaciones alternativas basadas en un modelo de desarrollo antineoliberal y tendientes a una economía post capitalista y a una forma alternativa de modernidad - una modernidad satisfactoria en palabras de García Linera (2007)—; y

b) proyectos descoloniales basados en un conjunto diferente de prácticas (por ejemplo, comunales, indígenas, híbridas y, principalmente, pluriverbales e 
interculturales), tendientes a una sociedad post liberal, a una alternativa a la euromodernidad.

El propio Escobar advierte que actualmente "podríamos hablar de tres escenarios: poscapitalista, posliberal y pos-estatista" (2010: 45). Tal cosa requeriría una radical transformación del monopolio de la economía del poder y del conocimiento, que hasta hace muy poco ha caracterizado a las sociedades modernas/coloniales. Un criterio básico para lograr lo anterior es determinar el carácter de los cambios y saber hasta qué punto están siendo cuestionadas las premisas básicas del modelo de desarrollo.

De acuerdo con Bretón (2010: 11-12), los reiterados y rotundos fracasos del desarrollo y las no menos estrepitosas frustraciones a que han llevado todos los intentos por encontrar vías o modelos de desarrollo alternativos, condujeron a algunos investigadores y analistas como Escobar (1998), Rist (2002) o Ferguson (1990) a apostar por una lectura en clave foucaultiana de tal marco histórico que apuntara a una salida posdesarrollista de ese atolladero conceptual, imaginativo y práctico. Es más, todos estos autores coinciden en advertir que no se debe tratar de ensayar más formas fallidas (por imposibles) de desarrollos alternativos, sino de buscar verdaderas alternativas al desarrollo como principios organizadores de la visión, posicionamientos e intervención sobre la realidad de la perspectiva posdesarrollista.

A su vez, trascender el desarrollo solamente será posible "fijando la atención en las culturas, los conocimientos y los imaginarios locales en la construcción de un futuro ajeno a la noción de desarrollo" (Bretón, 2010: 12). Así, una tarea clave en este sentido sería "la denuncia del capitalocentrismo implícito en los discursos recientes sobre la globalización" (Breton, 2010: 12-13). De ahí "la necesidad de fijar la atención en los márgenes del sistema, en las prácticas y proyectos locales, en las culturas substantivas realmente existentes e invisibilizadas por la meta del discurso desarrollista" (Escobar, 2000, citado en Bretón, 2010: 12).

Esto no quiere decir que el capitalismo, el liberalismo y las formas estatales dejen de existir, significa que su centralidad discursiva y social ha sido parcialmente desplazada, permitiendo así ampliar la gama de experiencias sociales existentes que son consideradas alternativas válidas y creíbles a lo que hoy predomina (Santos, 2007, citado en Escobar, 2010: 46).

No obstante, prácticas socioespaciales alternativas como las que desde la década de los noventa de la pasada centuria se vienen desarrollando en la Sierra de Santa Marta (Veracruz, México), articulan una potencialidad de cómo podría ser el mundo en otro contexto. Es en estos espacios locales donde "no solo se incuban, sino que se experimentan y analizan nuevos imaginarios e ideas acerca de cómo reensamblar lo socio-natural" (Escobar, 2010: 46-47). 


\section{Metodología de la investigación}

La metodología puede definirse como la estructura de procedimientos y reglas transformacionales por las que el científico extrae información y la moviliza a distintos niveles de abstracción con objeto de producir y originar conocimiento acumulado (Velasco y Díaz de Rada, 1997: 17). En base a esta definición, en este trabajo se han utilizado diversos métodos y técnicas de investigación propios de las Ciencias Sociales y más concretamente de la Antropología Social.

En términos generales, se puede decir que a partir de una metodología cualitativa, sustentada en los métodos de la investigación etnográfica y la aplicación de técnicas como las entrevistas abiertas y semiestructuradas con un enfoque de(s)colonial ${ }^{10} \mathrm{a}$ los actores sujetos de estudio (Gráfico 1), este trabajo ha identificado, analizado y etnografiado diversas experiencias de prácticas socioespaciales alternativas y transformaciones poseconómicas en la gestión de recursos naturales en las comunidades que configuran la Sierra de Santa Marta (ya descritas en el apartado 2 de este trabajo).

Las bases metodológicas de este trabajo se sustentan y tratan de combinar los principios de la "antropología activista" desarrollada por Hale (2008) y Speed (2006); sin embargo, durante la investigación han ido surgiendo nuevas opciones metodológicas que "pueden retroalimentar, rejuvenecer y descolonizar la clásica etnografía antropológica" (Dietz y Mateos, 2010: 9). De esto se puede deducir que, a su vez:

Se están generando cauces innovadores para diversificar el conocimiento universal y académico, para relacionarlo con conocimientos locales, etnociencias subalter-

\footnotetext{
${ }^{10}$ En este marco no se debe olvidar, o minimizar, el hecho de que las posiciones estructurales de los sujetos que habitan la herida colonial son el heterogéneo producto de un proceso histórico de dominaciónexplotación: el colonialismo. Y producto también de una "colonialidad del poder" (Quijano, 2000) entendida como un patrón que al hilo del colonialismo y tras racializarlos, jerarquiza a los sujetos estableciendo vínculos que delimitan y condicionan sus posibilidades de actuación y producción sea cual sea el campo (local o global) en el que éstos desean intervenir: el económico, político, el del conocimiento, el de la educación o el del arte. Desde esta perspectiva se plantea que la colonialidad, es decir, la "lógica cultural" del colonialismo, persiste reproduciéndose socio-lógicamente en los Estados-nación post-coloniales. De este modo, se utiliza el término decolonial, en tanto que la noción de colonialidad ha sido central en un proyecto, el de Modernidad/Colonialidad, desde el que diferentes autores y autoras latinoamericanos piensan la herencia colonial de las Américas como un proceso inconcluso, atendiendo a tres ejes estructurales: el del poder, el del saber y el del ser. De esta forma, se retoman las críticas que ha recibido la calificación de postcolonial aplicada a las relaciones actuales de dominación que mantiene los antiguos países colonialistas con las ex-colonias. Esta crítica se refiere, sobre todo, a la existencia misma del prefijo "post", en tanto que prefijo que presentaría las relaciones coloniales como algo superado. Así, el empleo de de-colonial en vez de des-colonial (con o sin guión), lo propuso Catherine Walsh como manera de distinguir entre la propuesta decolonial del proyecto Modernidad/Colonialidad, por un lado, del concepto de descolonización en el uso que se le dio durante la Guerra Fría, y, por otro, de la variedad de usos del concepto de post-colonialidad.
} 
nas y saberes alternativos, que en su confluencia se hibridizan mutuamente construyendo nuevos cánones diversificados, enredados y glocalizados de conocimiento. Este incipiente diálogo de saberes, que involucra dimensiones inter-culturales, interlingües e inter-actorales, a su vez, obliga a la antropología académica a replantearse sus conceptos teóricos básicos tanto como sus prácticas metodológicas, aún demasiado monológicas y monolingües (Dietz y Mateos, 2010: 9).

Gráfico 1. Identificación y agrupación de los distintos actores sociales sujetos de estudio

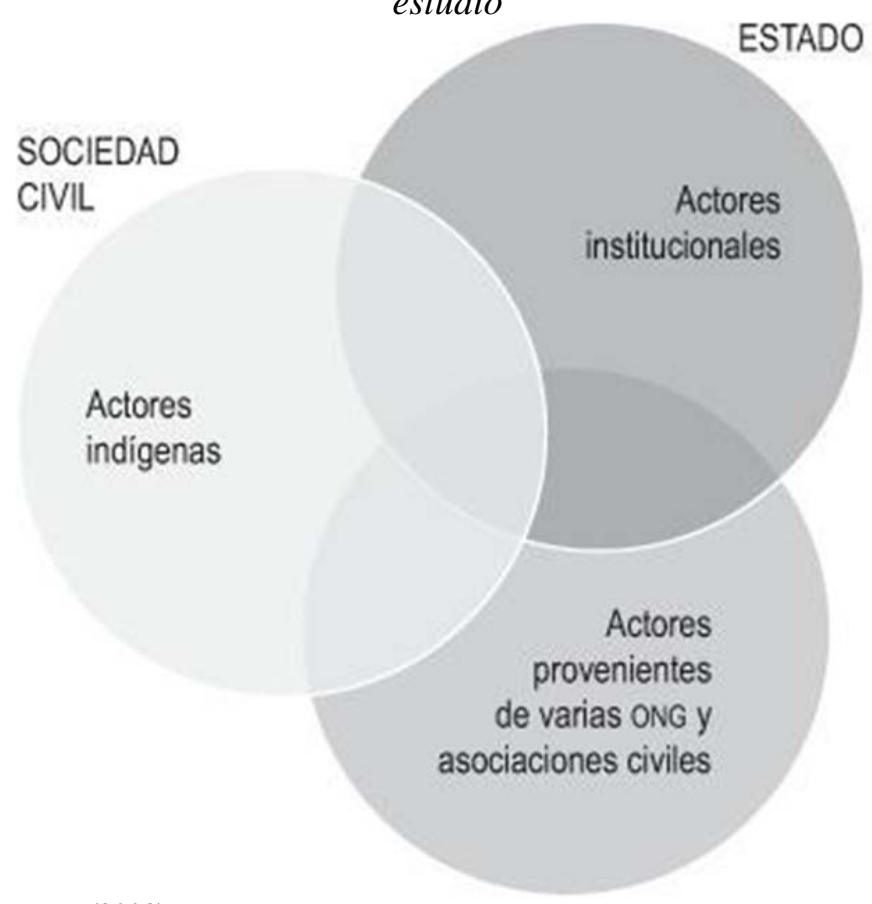

Fuente: Ávila y Mateos (2008).

Además, es un firme propósito de este trabajo poder contribuir en la medida de lo posible a una "antropología descolonizante y descolonizada" (Harrison, 1991: 5). Por ello, la praxis de este trabajo considera que "es indispensable partir del reconocimiento explícito de las relaciones asimétricas y dialécticas que existen a diferentes niveles" (Dietz, 2009: 109-110). Para este último autor estos niveles son:

1) Entre el investigador como persona, la ciencia como institución y el grupo estudiado, así como la o las sociedades del norte o del sur que constituyen el marco político-social que articula las relaciones entre estos tres elementos $[\ldots]$; 
2) entre el sujeto investigador, el sujeto investigado y las estructuras circundantes que condicionan y "objetivizan" de forma dialéctica la intersubjetiva relación de campo $[\ldots]$;

3) entre la investigación como tal y sus diferentes referentes y audiencias que interactúan como "comunidades de validación" y aplicación del conocimiento científico $[\ldots]$;

4) entre el conocimiento antropológico de origen occidental y hegemónico, centrado en el sujeto que protagoniza la investigación, y otras formas de conocimiento contra-hegemónico, centradas en los sujetos investigados [...]; y,

5) consecuentemente, entre un enfoque etic, necesariamente parcial, que sólo refleja la visión externa y estructural del fenómeno estudiado, y un enfoque emic, también parcial, centrado en la visión interna y accional del mismo fenómeno [...] (Dietz, 2010: 110).

Así, la resultante praxis etnográfica no se limita ni a la "introspección estetizante ni a la externalización movilizante" (Dietz, 2009: 111), sino que, mediante la negociación recíproca de intereses académicos y políticos, es posible generar una "novedosa mixtura de teoría y práctica" (Escobar, 1993: 386) que se traduce en "fases de investigación empírica, de teorización académica y de transferencia de praxis política" (Dietz, 2009: 111-112).

Como investigador he intentado en todo momento que esta transferencia no se reduzca a un simple acto de concienciación, sino que constituya un intercambio entre dos formas de conocimiento: entre el conocimiento generado por los expertos de su propio mundo de vida, por un lado, y el conocimiento geográfico y antropológico generado por el experto académico, por otro lado. Para ello, ha resultado esencial mi doble perspectiva como geógrafo y antropólogo y persona estrechamente vinculada emocionalmente al mundo rural agrario, por mi descendencia familiar de campesinos de la Sierra de Gredos (Ávila, España).

\section{Prácticas socioespaciales alternativas para la sustentabilidad en la Sierra de Santa Marta}

Considerando todo lo expuesto hasta aquí y a partir de la metodología de investigación descrita, se ha puesto de manifiesto que, tal y como denotan los fragmentos de entrevistas abiertas y semiestructuradas que se adjuntan a continuación, las incipientes prácticas socioespaciales de gestión integral, sustentable e intercultural de recursos naturales en la Sierra de Santa Marta albergan una serie de características convergentes con los planteamientos de modelos emergentes y alternativos al desarrollo como el etnodesarrollo, la participación, el empoderamiento (género), el diálogo de saberes y la colaboración intercultural, entre otros.

Asimismo, estos datos empíricos también resultan concordantes con los supuestos teóricos de enfoques económicos acordes a una nueva modernidad, así como a 
los principios de otras formas alternativas de relación económica no orientadas por la lógica de mercado, definidas como otras economías: alternativas, sociales y solidarias, antiutilitaristas, post desarrollistas, del trabajo, etc.

Ello convertiría a estas emergentes prácticas socioespaciales alternativas en diferentes de las que desde las políticas públicas del Estado mexicano, marcadamente de corte asistencialista y paternalista, se venían dando en la región de la Sierra de Santa Marta hasta la década de los noventa del pasado siglo XX.

En cambio, los enfoques de estas novedosas e innovadoras experiencias de manejo y gestión de recursos naturales, agrosilvopastoriles, pesqueros y ecoturísticos se muestran en la línea de la noción de sustentabilidad integral definida en esta investigación.

De este modo, estos proyectos se podrían presentar como posibles modelos alternativos (ecológicos, económicos, sociales, políticos, culturales y/o educativos) para contribuir a la mejora de la precaria realidad de las comunidades indígenas campesinas en aspectos de ineludible interés como el desarrollo humano, los derechos humanos, la vulnerabilidad, la justicia social, el cambio climático o la sostenibilidad ambiental.

\subsection{Experiencias emergentes de gestión integral, sustentable e intercultural de recursos naturales}

Para sustentar las afirmaciones anteriores se presentan de forma sintética algunos de los datos, evidencias, objetos y materiales empíricos arrojados por el trabajo de campo etnográfico realizado en distintas comunidades indígenas campesinas de nahuas y popolucas de la Sierra de Santa Marta entre octubre del año 2011 y septiembre del 2013.

El análisis se centra en las experiencias de manejo y gestión de los recursos naturales endógenos desarrolladas en interacción directa e intercultural entre la población local indígena campesina, técnicos y promotores campesinos de los proyectos no gubernamentales y/o civiles de la región y científicos o expertos académicos, tanto locales como foráneos.

Dentro del contexto de la Sierra de Santa Marta varias organizaciones no gubernamentales y/o civiles como el Proyecto Sierra de Santa Marta A.C. (PSSM), Desarrollo Comunitario de Los Tuxtlas A.C. (DECOTUX), Comité Intercomunitario de Cooperativas Agroforestales Texizapa-Huazuntlán (CICATH), Espacios Naturales y Desarrollo Sustentable A.C. (ENDESU) o la Universidad Veracruzana Intercultural (UVI) sede regional de Las Selvas, entre otras, desarrollan de forma colaborativa diversas alternativas de gestión y uso de recursos naturales que pretenden frenar la curva ascendente de destrucción de la todavía extraordinaria biodiversidad de la región y sentar las bases para transitar hacia un modelo de desarrollo más humano: 
Me parece muy importante cómo la gente acá trata de pensar en el bien común de toda la Sierra. Cuando todos nosotros entramos aquí la gente ya no tiene partido ni religión. Acá, nada más siempre todos pensamos en la restauración del medio ambiente. Lo demás todo se queda atrás. Cuando vienen las elecciones decimos: “Compañeros, vamos a ir a la reunión”, pero ahí nadie piensa ni dice yo soy rojo, tú verde, tú el azul, porque eso no existe. Si todos nosotros hubiéramos empezado con esa mecánica de que tú eres el rojo, tú eres el verde y demás lo más seguro que la organización ya no existiera. Entonces aquí la política y la religión se quedan fuera de las puertas de nuestras organizaciones. A veces, sí tenemos que discutir tercamente con algunos compañeros, pero, finalmente, después de la discusión llegamos a un acuerdo, lo anotamos en el trabajo de reunión y siempre, pues hasta ahorita, la organización permanece y así hemos logrado bastantes cosas (Campesino nahua y miembro del CICATH).

Para que estos nuevos modelos alternativos al paradigma desarrollista puedan llevarse a cabo bajo un enfoque de gestión de recursos naturales integral y sustentable, la restauración ambiental y ecológica constituye una fuente de ocupación laboral e ingresos económicos de las comunidades indígenas campesinas y tiene un triple impacto:

$1^{\circ}$. Ambiental, en el sentido en que se conservan o recuperan áreas forestadas, recursos hídricos o ecosistemas de gran valor ecocultural con un enfoque de reciprocidad con la naturaleza e iniciativas destinadas a combatir la pobreza rural:

La gente busca comprar árboles para su casita y ya no hay. Ya nadie te quiere vender porque la gente misma acabó con todo; acabamos, porque yo también me incluyo. Acabamos con todo para milpa, para potreros, incluso para el café también tuvimos que tumbar muchos árboles. Entonces ahorita estamos lamentándolo porque no tenemos ni para hacer una casa. La gente aquí se dedicó durante muchos años a la tala clandestina de madera y acabaron con todo. En mi predio antes de entrarle a los proyectos de DECOTUX y ENDESU ya prácticamente no había arbolitos. Esa agua llegó a bajar así, mire, completa, y la gente buscaba cangrejitos y pescaditos porque estaba muy bajito. Ahorita, con la reforestación, este año nunca se bajó el agua y va a crecer más cuando haya más árboles. Por eso decidimos meterle más árboles de aquel lado, para que de los dos lados ya tenga mucho árbol (Campesino nahua beneficiario de los programas del PSSM, DECOTUX, CICATH y ENDESU).

$2^{\circ}$. Económico, en la medida en el trabajo de restauración y/o conservación ambiental es adecuado y justamente retribuido a las campesinas y campesinos locales:

Hace tres años yo quería vender mi parcela porque necesitaba una lana. Me daban 400.000 pesos por las 15 hectáreas. Yo consulté con mi esposa si era viable vender o no y ella me dijo: “Aguántate tantito, lo mismo viene algún proyectito por ahí y hay para comer”. Nos aguantamos un año, cuando llegó lo de la reforestación y la restauración ambiental. Ahorita le digo al Ingeniero que una señora de Mina- 
titlán me ofrece 2 millones de pesos por mi parcela. Ahorita lo que pasa es que la gente, mucha gente, me ha preguntado que cómo está el proyecto, que si sale para comprar el maíz y yo les he dicho que sí, que es una ventaja para mí, que los tres años que estoy con lo de la reforestación con eso mismo de mi salario compro el maíz para toda mi familia. Mis hijos, mi esposa y yo trabajamos aquí y entonces ganamos una parte de ese recurso para comprar la comida y comprar el maíz (Campesino popoluca beneficiario de los programas del PSSM, DECOTUX, CICATH y ENDESU).

$3^{\circ}$ ) Social, en tanto que contribuye al fortalecimiento del tejido social con una perspectiva ambiental integral y sustentable desde la gestión colaborativa intercultural:

Así, ahorita yo le digo a mis hijos: "Yo no les voy a dejar como herencia dinero en efectivo pero sí les dejo una planta, eso es una herencia que les va a quedar ahí”. Luego también el terreno. También ellos. Hay veces que les dices: "Puedes vender un árbol". No, ellos te dicen: "No, no lo vamos a vender porque lo vamos a necesitar". Así, yo le digo al Licenciado: "Para mí que esto que hemos creado acá en mi predio yo lo quiero dejar como una parcela demostrativa para que la gente se dé cuenta que no con muchos recursos, pero con la colaboración y ayuda de todas las gentes que andamos por acá en la región, se puede reforestar, restaurar ambientalmente los manantiales y llenar todo el año el estómago con ello y no tener que marcharse lejos para encontrar chamba" [coloquialmente en México se le dice así al trabajo] (Campesino nahua beneficiario de los programas del PSSM, DECOTUX, CICATH y ENDESU).

Asimismo, el trabajo comunitario e intercultural cercano y sistemático entre todos los actores locales de la Sierra de Santa Marta, a partir de la metodología de la investigación participativa, es fundamental para que en los últimos lustros se esté logrando, gracias a las iniciativas generadas desde estas organizaciones intercomunitarias e interculturales, cierta suficiencia alimentaria y económica basadas en la utilización de los diversos recursos naturales endógenos de que disponen. Esto en absoluto significa que sean unas comunidades encerradas en sí mismas. Por el contrario, la autosuficiencia se da gracias a la conservación y utilización de recursos de la selva mediante su integración en los mercados local, regional, nacional e, incluso, internacional:

El ingeniero está sembrando muchas plantas. Ésta es, seguramente muchos lo conocen, la pimienta, la pimienta gorda [Pimienta dioica]. Ésta la seleccionamos porque nosotros tenemos el vivero comunitario y el ingeniero nos reparte plantas a todos nosotros, y ya tenemos muchas plantas sembradas de pimienta gorda, que ahorita está a diez pesos el kilogramo. Esto desde siempre la gente lo siembra mucho aquí. Porque en agosto todo el pueblo indígena sufre una crisis que no hay maíz y con esto van, cortan su producto, lo venden y compran el maíz necesario para llenar 
el estómago, porque en el tiempo de agosto es cuando da la producción esta pimienta. Yo principalmente ahorita vendí como media tonelada de pimienta aquí mismo. Acá ahorita hay muchos compradores que vienen a comprar hasta acá desde Puebla, de Orizaba, vienen de aquí de Xalapa, la pimienta la pelean mucho. Yo puedo vender 10, 20 o 30 kilos de semilla de pimienta y con ello ya tengo un recurso con lo que puedo comprar mi maíz y los víveres para mi familia para toda la temporada (Campesino popoluca beneficiario de los programas del PSSM, DECOTUX, CICATH y ENDESU).

Por lo tanto, en un contexto en el que el problema fundamental no es la gestión de un recurso aislado, sino la gestión de un ecosistema, los principios de la sustentabilidad integral sólo se pueden llevar a cabo mediante la consecución de acuerdos comunitarios interculturales para aplicar unos determinados principios, como el etnodesarrollo, la participación y el empoderamiento (género) de las poblaciones locales, basados en el respeto escrupuloso de las peculiaridades agroecológicas y culturales de cada región:

De este lado de la Sierra de Santa Marta la verdad es que la plantación y producción de pimienta es incipiente [...] y lo que hacemos es ir rescatando especies que son útiles para la zona, útiles para el productor, con criterios de selección por consenso; porque de pronto nosotros no podemos imponer, o sea, no podemos traer cosas de fuera e imponerlas acá, porque hay cosas en la región que son muy valiosas y son las que debemos respetar, valorar e impulsar (Ingeniero agrónomo y técnico/promotor campesino popoluca de los proyectos PSSM y ENDESU).

Además, estas incipientes experiencias trascienden la incapacidad del desarrollo oficial instaurado tras la expansión tras la Segunda Guerra Mundial para incorporar a las mujeres al ideal emancipatorio y empoderador del mismo, y para avanzar en una mayor equidad de género:

Yo cuento con un terrenito de 9 hectáreas. Entonces tengo 7 hectáreas de empastado donde andan 11 animalitos y en 2 hectáreas tengo sembrado café. Primero reforesté. Tengo un manantial. Sembré plantas y todo y ahora le metí café y otras plantas maderables muy productivas que me dio el Ingeniero. Ahora en mi parcela hay agua, madera, leña, proteínas y mis animales (ganado de ahorro). Entonces, yo que soy sola con mis dos hijos, pues mi esposo ya falleció, y trabajo solamente con mi papá de 92 años, puedo decir que gracias al proyecto del Ingeniero mi parcela y mi vida ha mejorado mucho. ¡Demasiado! Yo le dije al Ingeniero: “Mi parcela tiene que ser la número uno, no porque sea yo mujer, pero yo les voy a ganar a esos señores que entraron junto conmigo al proyecto", y según me dijo el Ingeniero, sí, mi parcela es la número uno, o sea, iya les gane! (Campesina popoluca beneficiaria de los programas de ENDESU). 
Conjuntamente, todos los aspectos anteriores resultarían ser un ejemplo de cómo algunos de los recursos tradicionales de la selva han permitido a algunos campesinos y campesinas indígenas locales, en condiciones bastante adversas para la producción agropecuaria, evitar en alguna medida tener que abandonar temporal o definitivamente sus comunidades originarias:

Pues realmente, anteriormente antes había acá en la Sierra un montón de árboles y la gente decía: ¿para qué sembrar más? Además, solamente los utilizaban para sacar leña pero no para sacar muebles y otros productos de la selva. Pues ahorita, por ejemplo, en los proyectos en los que andamos los campesinos de la región, promotores, técnicos, tanto de acá como de fuera y nosotros, los profesionistas, egresados y estudiantes de la Licenciatura en Gestión Intercultural para el Desarrollo (LGID) de la UVI-Las Selvas [sede regional de las Selvas-Huazuntlán de la Universidad Veracruzana Intercultural en la Sierra de Santa Marta] los árboles cortados se han utilizado de modo más integral y sustentable para hacer muebles, juguetes, artesanías y otras cositas para comerciar y para la venta. Así, muchas familias han sacado para comer y vivir mejor todo el año y no han tenido que emigrar lejos (Joven nahua egresado de la Licenciatura en Gestión Intercultural para el Desarrollo, Orientación en Sustentabilidad, de la Universidad Veracruzana Intercultural-Las Selvas).

\section{Resistencias indígenas interculturales frente al poder del modelo desarrollis- ta hegemónico capitalista}

Dentro de la variada gama de propuestas productivas integrales, sustentables e interculturales que en los últimos años diferentes organizaciones no gubernamentales vienen impulsando en la región de Los Tuxtlas y la Sierra de Santa Marta, el proyecto denominado Desarrollo Comunitario de Los Tuxtlas A.C. (en adelante DECOTUX) conlleva unas prácticas de gestión y manejo de los recursos naturales, agrosilvopastoriles, pesqueros y ecoturísticos con un enfoque holístico de cuenca hidrográfica.

6.1. Gestión integral de recursos naturales con enfoque holístico: la cuenca hidrográfica

Desarrollo Comunitario de los Tuxtlas A. C. (DECOTUX) es una asociación civil no gubernamental que tiene como objetivo la formación y el fortalecimiento de las capacidades técnicas y de gestión de la población rural de la región de los Tuxtlas y la Sierra de Santa Marta con enfoque autogestivo. En consecuencia, DECOTUX viene trabajando desde hace varios lustros en la capacitación, experimentación, promoción y gestión de proyectos y propuestas tecnológicas, productivas y de manejo ambientalmente adaptadas, que requieran de un mínimo de insumos exter- 
nos y que sean apropiables ecológica, económica y culturalmente por la población local.

Desde DECOTUX se trabaja con un enfoque territorial integral, y en los últimos años la asociación ha buscado abordar proyectos bajo el marco geográfico holístico de la cuenca de los ríos Texizapa-Huazuntlán. De esta manera, la cuenca hidrográfica como principal criterio geográfico natural utilizado para definir la delimitación de del área de actuación de DECOTUX, la cuenca del río Texizapa-Huazuntlán, constituye otra unidad importante para la gestión y planificación integrada del medio debido a su cohesión geográfica y a un elemento integrador tan claro e importante como es el recurso del agua. La cuenca hidrográfica, aparte de un excepcional soporte físico para la regionalización, puede ser también un interesante ámbito espacial para la gestión integral del medio, organizándola en torno al elemento integrador del agua.

$\mathrm{Y}$ es que los ríos tienen, "en primer lugar, una evidente entidad como ejes de culturas, de civilizaciones, de caminos; segundo, como soportes de células de comarcas funcionales; tercero, por la misma posibilidad del básico uso del agua y, cuarto, por la adaptación del sistema territorial humano a los sistemas múltiples interconectados como canales terrestres de sus redes de valles en cada cuenca hidrográfica, dando lugar a entidades históricas asociadas a regiones físicas" (Martínez de Pisón, 2004: 45). Este es el caso de la interacción entre las comunidades indígenas campesinas de la Sierra de Santa Marta y las ciudades del sureste del estado de Veracruz.

Otra de las misiones principales de DECOTUX es la promoción del desarrollo integral con sustentabilidad y participación social. Para este fin se toma como eje la facilitación de acuerdos de cooperación entre los pobladores de áreas urbanas usuarias de agua ${ }^{11} \mathrm{y}$ otros recursos ambientales, y los de zonas rurales propietarios o usuarios productivos de los ecosistemas hídricos.

El eje de esos acuerdos es la restauración y conservación ambiental de los ecosistemas y agro-ecosistemas rurales de la Sierra de Santa Marta a través del mejoramiento de la calidad de vida rural. Esto se lleva a cabo mediante un esquema denominado inversión social para la sustentabilidad, como una forma de acción local-regional contra los diversos y complejos riesgos del cambio climático global.

Además, entre los principales objetivos de DECOTUX, se encuentra el contribuir a la recuperación ambiental de la cuenca del río Texizapa-Huazuntlán. Este

\footnotetext{
${ }^{11}$ La región de Los Tuxtlas y la Sierra de Santa Marta, con gran parte de su territorio incluido dentro de la Reserva Especial de la Biosfera de Los Tuxtlas, incluye 53 comunidades, en donde habitan más de 25.000 habitantes. Sin embargo, si incluimos la zona de influencia, son más de 350.000 los habitantes que, de una manera $\mathrm{u}$ otra, dependen de los servicios ambientales de esta área natural protegida. Si a esto agregamos la población de la zona urbano industrial-petrolera de Coatzacoalcos-Minatitlán-Cosoleaque, está cifra rebasa el millón de habitantes.
} 
espacio geográfico aporta aproximadamente el $75 \%$ del agua para el consumo humano de ciudades del sureste de Veracruz como Acayucan, Jáltipan, Cosoleacaque, Minatitlán o la gran aglomeración urbana de Coatzacoalcos ${ }^{12}$, así como de 13 comunidades de los municipios rurales de Soteapan, Mecayapan, Tatahuicapan de Juárez y Pajapan (Mapa 1).

No obstante, esta cuenca hidrográfica de montaña ha estado sujeta a un intenso uso productivo (ganadería extensiva) que ha modificado los ecosistemas y, por ende, las condiciones de recarga de mantos freáticos y cuerpos superficiales. La continua extracción de agua ha generado, además, conflictos entre las comunidades y las ciudades usuarias por el pago de derechos por el acceso al agua y para destinar recursos para la conservación de la cuenca. Así, según un representante legal y técnico/promotor de DECOTUX:

Para Decotux A.C. resulta esencial contribuir a la recuperación ambiental de la cuenca que aporta el agua para el consumo humano de ciudades del complejo petroquímico del sur de Veracruz como Acayucan, Jáltipan, Cosoleacaque, Minatitlán o Coatzacoalcos y de 13 comunidades de la Sierra de Santa Marta. Para ello es necesaria la consolidación de un espacio de planeación participativa amplio y plural, que instrumente un modelo sustentable de manejo de cuenca y gestione fondos para su aplicación en las 13 comunidades que se ubican en la cuenca del río Huazuntlán, en la sierra de Santa Marta y en la Reserva de la Biosfera de Los Tuxtlas [Caudillo Emiliano Zapata, Benigno Mendoza, Tatahuicapan, Ocotal Texizapa (municipio de Tatahuicapan de Juárez); Plan Agrario, Encino Amarillo (municipio de Mecayapan); Ocotal Grande, Ocotal Chico, Mazumiapan Chico, Soteapan, Ocozotepec, San Fernando y Santa Marta (municipio de San Pedro Soteapan) y las cabeceras de los municipios urbanos de Acayucan, Minatitlán y Coatzacoalcos]. Nuestra historia comienza, como muchas de otros proyectos en la región, con una situación de desastre causado por años de deforestación propiciada por políticas públicas ambientalmente erróneas (Representante legal y técnico/promotor de DECOTUX).

En este contexto, desde hace décadas se viene reproduciendo una compleja y conflictiva relación entre campo y ciudad en torno a la extracción de agua y, sobre todo, al proceso organizativo que se impulsó a partir de una iniciativa de investigación-acción a raíz del cual se conformó el Comité Intercomunitario de la Microcuenca Texizapa-Huazuntlán. Desde esta organización se plantearon una serie de acciones para la restauración y manejo de esta microcuenca que son ahora objeto de negociación con los organismos operadores de agua de las ciudades de Coatzacoalcos y de Minatitlán y otras instituciones de los gobiernos federal y estatal.

\footnotetext{
${ }^{12}$ Coatzacoalcos y Minatitlán son municipios estratégicos. Ambos constituyen una región portuaria petroindustrial de importancia nacional en la economía de México, y usan el agua de la cuenca del arroyo TexizapaHuazuntlán (5.852 ha.) para abastecer las necesidades de consumo humano y comercial.
} 
En el año de 1984 se construyó en la confluencia de los arroyos Texizapa y Xonoapan, en el ejido de Tatahuicapan (municipio de Mecayapan), la presa potabilizadora de Yuribia ${ }^{13}$ que capta entre 800 y 1.200 litros de agua por segundo para el consumo doméstico de las ciudades de Coatzacoalcos y Minatitlán, entre otras del sureste veracruzano. Esta extracción de agua de las cuencas hidrográficas de la Sierra de Santa Marta, y especialmente del ejido de Tatahuicapan, por parte de las grandes ciudades industriales petroquímicas de su entorno, perfiló a esta región serrana como área estratégica para el desarrollo industrial del Sur de Veracruz. Así, como parte de un programa de desarrollo industrial del sureste de México, en 1984 se construyó la presa Yuribia para asegurar la viabilidad de las ciudades de Coatzacoalcos y Minatitlán como polos de desarrollo regional.

El 75\% de la población de estas ciudades industriales satisface sus necesidades domésticas con agua proveniente de la presa de Yuribia. La extensión de la cuenca de captación de estos arroyos es de 5.852,9 ha distribuidas entre 10 ejidos con todo o parte de su territorio dentro de la Sierra de Santa Marta. Desde la construcción de la presa, las comunidades indígenas campesinas serranas opusieron resistencia organizada para demandar beneficios sociales en reciprocidad por el agua extraída de sus territorios:

Tomen Yuribia y nosotros vamos a Platanillo [principal manantial que dentro de la Sierra de Santa Marta abastece a la presa de Yuribia] y el Gobierno de esa manera va a tener que actuar. Porque yo le digo que al gobierno si le pide uno a las buenas no lo da. La verdad, no lo dan. Y yo le digo esto porque yo trabajé 19 años con el Consejo Regional de Productores Cafetaleros. Hay un recurso para el sector cafetalero para levantar la cosecha, para fertilizar las plantas, pero nunca nos lo dan a la buena. Vamos a las Comisiones y nos dicen: espérense tantito, pero nunca nos lo dieron. Llega el tiempo y no hay recurso. Ya cuando nosotros lo vemos difícil, vamos y tomamos Platanillo y entonces sí vinieron los helicópteros, patrullas, todo el ejército, ¿no? Aquí están las pruebas, ya hemos ido miles de ocasiones. Aquí está toda la gente, miles de personas que nos estacionamos y decimos: "Mátennos si quieren para que ya no volvamos a calentar la cabeza al gobierno". Y el gobierno tiene que actuar. Y siempre hemos actuado de esa manera. $Y$ yo les he hablado y les digo: "Ahora sí, es de nosotros, estamos trabajando, tenemos la muestra y no lo estamos pidiendo flojamente, porque el que lo pida flojamente tienen derecho de que desde el gobierno no les apoyen". Y yo estoy muy inconforme sobre esto porque el gobierno ya no apoya al pueblo indígena, quien estamos manteniendo aquí lo que son los bos-

\footnotetext{
${ }^{13}$ A través de la planta potabilizadora Yuribia se captan los escurrimientos de varios arroyos y manantiales para abastecer las necesidades de consumo humano de dos de las ciudades petroindustriales más importantes de México: Coatzacoalcos y Minatitlán, cuya población llega al medio millón de habitantes en conjunto. La captación es de 800 a 1.000 litros por segundo, mientras que las necesidades actuales rebasan los $1.600 \mathrm{l} / \mathrm{seg}$. Se prevé que las necesidades se estabilizarán entre 1.800 y 1.900 1/seg. La extensión total de la subcuenca es de 5.852,57 ha y la población de unos 13.000 habitantes.
} 
ques y los manantiales. Si usted se va por aquí rumbo a Mazumiapan, toda esa serranía, mire, usted verá como hay aguajes, pero, ¿por quién? Por nosotros que ya no lo estamos destruyendo, somos quienes lo estamos manteniendo y dejándolo que crezca. Pero, ¿con qué nos pagan? Con nada. ¿Y quién se gana el dinero? El gobierno que cobra la luz. Es como la Comisión que a nosotros nos cobra la luz y si no pagamos nos la cortan y entonces nosotros tenemos también ese derecho de que nos den porque tenemos aguajes (Campesino popoluca beneficiario de los programas de DECOTUX y CICATH).

Inicialmente el argumento jurídico de las instituciones de gobierno que buscaban resolver un problema técnico para la prestación de un servicio básico a miles de personas, se basaba en el artículo 27 constitucional que establece que el agua es un bien común. El argumento no fue rechazado por las comunidades indígenas, pero los representantes campesinos sostuvieron sus demandas explicando que no eran contrarias a la constitución.

En este marco, las diferentes percepciones sobre los derechos acerca del uso del agua sólo pudieron ser conciliadas mediante la propuesta de un acuerdo de reciprocidad, a través del cual las comunidades obtendrían recursos (escuelas y caminos) y servicios (clínica de salud, red de distribución de agua, infraestructura urbana, etc.) para su desarrollo.

Desde entonces, las prioridades distintas de los actores sociales generan tensiones que no han favorecido el acercamiento y el diálogo. Por el contrario, junto con otra compleja serie de factores, han dificultado el poder atajar adecuadamente las amenazas que se ciernen sobre el ecosistema regional y sobre el abasto de agua para las comunidades serranas y las ciudades:

De acá es todo el agua que va a parar a Coatzacoalcos, Minatitlán, Cosoleaque, Jáltipan o Acayucan. Es toda agua que viene de aquí, de esta región de Santa Marta y de la presa del Yuribia. Entonces yo hablé con el representante de DECOTUX y le dije: "Organiza el resto de comunidades que yo organizó a Soteapan, que nosotros estamos bien organizados, solo falta que como la avispa nos den y entonces el gobierno va a soltar, verás cómo va a soltar". A nosotros nos toman como gente muy, como le diré... revoltosa. Yo he ido con el Gobernador hace poco y me ha dicho: "Miré, nosotros es que a Soteapan los tomamos como gente muy revoltosa porque si no se les da, ustedes lo toman...". Y yo le digo: "Pues nosotros tenemos ese derecho gobernador". Ahorita nosotros vamos a hacer un plantón no sé si este mes [Agosto de 2012] porque no nos pagaron 1.700 .000 pesos de plantas de café de un vivero. Entonces ahorita vinieron los técnicos supervisaron y están las plantas y ya nos dijeron que ahora no hay recursos y ya les dejamos un plazo que si este mes de agosto no nos pagan pues entonces les dejamos un plazo y si no ya estamos organizados para tomar Platanillo. Porque eso es cosa de los productores del agua (Campesino popoluca beneficiario de los programas de DECOTUX y CICATH). 
Por otra parte, pese a que el ejido Tatahuicapan donde se construyó la presa de Yuribia se ubicaba en el municipio de Mecayapan, fueron actores de otro municipio vecino, Tatahuicapan de Juárez, quienes negociaron el acuerdo (autoridades ejidales y de la asociación ganadera local de Tatahuicapan de Juárez).

Asimismo, debido al carácter complejo de la relación entre Coatzacoalcos y Tatahuicapan de Juárez, se ha establecido entre ellas una relación de intercambio poco transparente, en donde ha prevalecido una interlocución informal con actores comunitarios diversos (presidente municipal, presidente de la junta de mejoras, directores de escuela, etc.), muchos de los cuales buscan fortalecer ámbitos propios de poder o gestión. Esta situación ha alimentado la desconfianza entre actores y ha atomizado los recursos en apoyos dispersos, escasos e intermitentes a los campesinos:

En el 2008 nosotros fuimos junto con un compañero biólogo y el gerente y representante legal de DECOTUX a la Cámara de Diputados y presentamos nuestro proyecto. En ese proyecto nosotros pedíamos una camioneta y nos dijeron que no porque si no es seguridad pública o si no es salubridad no se puede. Entonces nosotros nos estamos dando cuenta de cómo los chinguentes diputados están ciegos, no se dan cuenta de lo que la gente necesita acá y eso a mí me ha dado coraje, y cuando hay oportunidad y puedo se lo digo en reuniones. No es justo que a la gente que más necesita los marginen y los dejan ahí con las migajas. ¿Qué es lo más importante? El planeta se está tambaleando y nosotros tenemos la culpa ciertamente, pero desde acá ya estamos haciendo algo y para todo esto que decimos nosotros que queremos que exista se necesitan recursos. De puros sueños no vive la gente, ni de promesas como hacen los políticos tampoco y lo vemos cuando dicen en sus discursos. Nos dicen: "Es que ya hay miles de millones de pesos para el programa PROARBOL, para la reforestación”. Eso es una vil mentira. ¿Cuánto nos llega acá? ¿Cuánto le llega a la gente? ¿Cuánto tenemos que hacer con el proyecto, que nos lo van encasillando, que le van poniendo miles de trabas para venirte a dar 200.000 pesos? ¿Cuánto se hizo allá? ¿Cuánto se gastó allá? Para que a la gente le llegue una mínima parte y la gente entonces dice: "Tú te estás robando el dinero porque viniste y me prometiste el dinero", cosa que no es cierto, y entonces la gente la toma con uno. Pero si nosotros no hacemos eso deben de existir los mecanismos y que las universidades nos ayuden a llegar a las cámaras y que los diputados y los senadores creen una ley para que parte de los recursos que la Hacienda da, así como lo da para seguridad y el ejército, que hasta para helicópteros y barcos hay, para lo forestal y el agua no existe. Pero debe existir en la ley mexicana que todos los años exista un valor cada año, que haya un monto, porque ellos ya saben que aquí estamos haciendo trabajos muy importantes, pero se hacen sordos y están ciegos y mudos también porque no se dan cuenta de cual es lo más importante. Yo no lo veo que a seguridad pública le den tanto, tantas camionetas, tanto armamento, tanto dinero para el ejército y ellos que han venido a hacer aquí. Y la gente está haciendo mucho esfuerzo. Yo me doy cuenta cómo han dejado sus áreas donde sembraban maíz, donde sembraban frijoles y sembraron arbolitos para mantener los manantiales que dan el agua para las grandes ciudades y ¿qué están sacando? A la gente a veces se le va el ánimo a los zapatos y 
me dicen: "Mira ya tiene tanto tiempo que yo tengo los arbolitos y ahorita las áreas riparias ya hace cuatro años que no hemos podido darle mantenimiento porque no ha habido recursos y está el 1\% ahí y está guardado y se lo están gastando y quien sabe lo que están haciendo y para el fin que fue creado el Fidecomiso ABC [AguaBosques-Cuenca]"14 (Campesino popoluca y líder-promotor-técnico de CICATH).

La falta de cumplimiento del acuerdo de financiamiento de infraestructuras y equipamientos básicos para las comunidades de la Sierra, la ausencia de espacios de participación y de mecanismos de transparencia, así como las distintas prioridades de los actores sociales implicados en la cuestión derivó en diferentes conflictos, inseguridades en el abastecimiento de agua a las ciudades y en un problema permanente de gobernabilidad a lo largo de veinte años.

En este contexto, un equipo de académicos de la Universidad Nacional Autónoma de México (UNAM) y miembros de organizaciones de la sociedad civil (DECOTUX, A.C., y SENDAS, A.C.), junto con la población local, trabajaron a lo largo de tres años para impulsar la creación de espacios para negociar una justa compensación por los servicios ambientales aportados por el área rural indígena campesina. Esta compensación se aplicaría desde un plan de desarrollo regional basado en ordenamientos ecológicos comunitarios.

Sumado a esto, otro motivo de controversia es que los beneficios del acuerdo se han concentrado en las zonas más bajas de la Sierra de Santa Marta, sin que las comunidades de las partes media y alta de la cuenca hayan obtenido ninguna participación ni beneficios, a pesar de ser en esos sectores donde se dan los principales procesos de captación hídrica. Mientras tanto, el paulatino deterioro ambiental está afectando las condiciones originales de la oferta de agua y amenazando el abasto urbano, principalmente durante los períodos secos:

Para mí lo más importante son los manantiales. Sí, porque como se lo digo a todos los que vienen por acá de las ciudades: a nosotros no nos afecta tanto el problema porque estamos en donde brota el agua, en los manantiales y aquí no se va a agotar el agua, pero abajo, en las ciudades sí. En la zona de Coatzacoalcos y Acayucan, principalmente, allí donde consumen el agua, sí... Yo recuerdo que fuimos una vez a Coatzacoalcos con el presidente y él nos dijo que nos iba a dar a apoyos de no sé cuántos millones y al final nunca dio ese recurso. Iba a dar un millón, y nunca dio ese recurso, y ellos son quienes consumen el agua que brota acá arriba en

\footnotetext{
${ }^{14}$ El Fideicomiso ABC (Aguas, Bosques y Cuencas) es una iniciativa del Sector Agropecuario, Rural, Forestal y de Pesca del Gobierno del estado de Veracruz. Se trata de un fondo público conformado por aportaciones económicas de los tres niveles de Gobierno, así como de particulares (industrias, asociaciones agropecuarias y forestales, cámaras empresariales, de la cooperación internacional y usuarios del agua en general).
} 
la Sierra (Campesino nahua beneficiario de los programas de DECOTUX y CICATH).

Precisamente, al socaire de lo acontecido en la Sierra de Santa Marta con el evento denominado por excelencia como "la tromba" se incorporó DECOTUX a los programas de Cuencas y Ciudades del Fondo Mexicano para la Conservación de la Naturaleza (FMCN) y de la Fundación Gonzalo Río Arronte (FGRA).

A partir de esto se fortaleció un flanco estratégico de acción para la restauración de la cuenca: la participación de las sociedades urbanas en las actividades de la cuenca alta mediante su incorporación a una instancia de acuerdo, gestión y decisión, que en este caso fue el nacimiento dentro de DECOTUX del Comité Intercomunitario de Cooperativas Agroforestales de la Cuenca del Arroyo TexizapaHuazuntlán (CICATH). Con ello se dio respuesta a la búsqueda de los espacios y las instituciones adecuadas para la gestión de diversos proyectos para el desarrollo integral y sustentable de la cuenca Texizapa-Huazuntlán:

Entonces la idea es que ya hemos aprobado el proyecto del Cuenca Tour. Ya se abrió una cuenta y ya estamos trabajando en el plan de negocio y entonces éste es el primer Cuenca Tour que hará su recorrido por la Sierra. Entonces dentro de poco ya vamos a tener los paquetes turísticos con las rutas bien ordenadas y todo lo demás. Entonces nuestra idea no es precisamente el ganar dinero sino el educar ambientalmente a la gente que vive allá abajo en las ciudades. Nosotros hemos estado en reuniones y es que nos dicen: "No sabemos qué piden ustedes porque nosotros acá abajo abrimos las llaves y sabemos que hay agua”. Pero la cuestión es que de-

\footnotetext{
${ }^{15}$ Los cambios antrópicos, fundamentalmente a través de la ganaderización y la deforestación, en la ecología de la Sierra de Santa Marta se vieron agravados por una "tromba" sin precedentes en la noche del 26 de junio de 2006, que generó daños cuantiosos en el territorio y afectó a parcelas productivas e infraestructura de abasto de agua para las ciudades de la región del sur de Veracruz. En los meses previos al desastre, DECOTUX A.C. ya había realizado un diagnóstico ripario que reflejaba las condiciones de deterioro de una importante extensión de estas áreas. Empero, no todo lo que trajo la tromba de junio de 2006 fue destrucción. La respuesta social fue la organización de las comunidades en cooperativas intercomunitarias (CICATH) y la elaboración de un plan de manejo de cuenca para la disponibilidad del agua. El gobierno de Veracruz al observar el impacto de la tromba solicitó el decreto de desastre y recursos del Fondo de Desastres Naturales (FONDEN) para resolver la problemática. Puesto que las comunidades presentaron una propuesta de plan de acción acorde a las circunstancias, el gobierno estatal entregó la administración de los fondos a las comunidades que se organizaron en cooperativas para responsabilizarse del ejercicio de los fondos. En este contexto y teniendo el problema de los derrumbes como antecedente más inmediato, el plan de trabajo de las comunidades, a través de sus cooperativas, se centró en 6 actividades: restauración/conservación de áreas riparias; restauración/conservación de nacimientos hídricos; restauración de derrumbes; reforestación (cambio de uso del suelo); conservación/restauración de cafetales (conservación productiva); e inducción de regeneración de vegetación en las partes altas de la cuenca (en zonas altamente deterioradas en zona núcleo). Sus resultados fueron: 600 manantiales reforestados; 300 derrumbes restituidos; 750 ha reforestadas; $250 \mathrm{~km}$ de áreas riparias reforestadas; 250 ha de café con mantenimiento; expedición a zona núcleo para inducción de semilla; un vivero y un equipo humano interétnico e intercultural.
} 
trás del agua hay una gran historia. La gente de ahí abajo no sabe lo que sucede aquí arriba. Que aquí existe mucha gente que tiene carencias y viven pobres y que hacen muchas cosas para que el agua les llegue ahí abajo. Entonces la finalidad más importante del Cuenca Tour es traer a gente de abajo, de las ciudades de la Cuenca, de Coatzacoalcos, de Minatitlán, de Cosoleacaque, de Jáltipan, de Acayucan y hacer estos recorridos y decirles: "Miren estos arbolitos son estos y estos, y se llama así y así, sirve para esto y para esto y hay tantos”. Entonces como ya existe un catálogo de especies forestales y otras muchas cosas que se han hecho. Son trabajos que se han hecho y hay muchas otras por sacar para adelante que también serían muy importantes, pero que ahorita no lo podemos hacer por falta de recursos (Campesino popoluca y promotor/técnico de CICATH).

Por lo tanto, el reconocimiento del importante papel que también representan en la cuestión del agua los actores urbanos ha resultado de gran trascendencia para darle verdadera fuerza a la gestión del CICATH. Ello permitió a esta organización, desde su condición indígena y campesina y con sus antecedentes de trabajo de restauración forestal e hídrica, alcanzar una gestión de 10 millones de pesos desde el año 2010. A su vez, otro organismo dependiente de DECOTUX y el CICATH como el Subcomité de Cuenca es una instancia de la estructura del Fideicomiso ABC (Aguas-Bosques-Cuenca), de la Secretaría de Desarrollo Agropecuario del Gobierno del estado, que también pretende incorporar a los actores de la sociedad civil al manejo y gestión sustentable de los recursos naturales del estado de Veracruz.

Por otro lado, desde su constitución e integración en DECOTUX y CICATH, la representación del Subcomité de Cuenca ha recaído en las comunidades campesinas de la cuenca alta de la Sierra de Santa Marta, conviviendo interculturalmente en él popolucas, nahuas y mestizos. Así, la inter-etnicidad y la interculturalidad son conceptos en construcción que responden a una visión dinámica de la realidad; interculturalidad que es posible entender como una cualidad atribuible a cualquier relación entre distintas culturas, lenguas y actores en donde se reconoce y se práctica la diversidad y la pluralidad cultural:

Dentro del vivero de DECOTUX parece que verdaderamente se ha logrado trabajar conjuntamente y mano a mano con popolucas y con nahuas, que históricamente ha sido bien difícil porque incluso dentro de las propias comunidades de popolucas y nahuas los conflictos intraétnicos que existen hacen social y culturalmente bastante complicado ponerse de acuerdo entre ellos. El vivero forestal comunitario es algo así como el corazón del proyecto. La experiencia que se ha vivido aquí con el vivero y con los viveristas es realmente fantástica y verdaderamente interétnica e intercultural. Entonces aquí C., que es de Ocotal Grande, habla nahuált y E., que es de Mazumiapan Chico, habla popoluca. Entonces desde que se empezó el proyecto, allá por el año 2007, ellos han sido los viveristas. Entonces entre todos, viveritas locales, técnicos y campesinos/as hemos acumulado un montón de experiencias e intercam- 
biado muchos saberes y conocimientos (Técnico mestizo de DECOTUX y asesor de CICATH y el Subcomité de Cuenca).

Entre otras múltiples cuestiones de decisiva importancia para la sustentabilidad integral de las comunidades indígenas campesinas de la Sierra de Santa Marta, desde el año 2010 DECOTUX A.C. ha logrado crear alianzas que atacaron otros frentes dentro del Plan de Manejo de la Cuenca, como son los aspectos sociales de vivienda y salud, bajo el enfoque de que no puede haber restauración ambiental sin restauración social:

A veces hemos pasado por muchas cosas y muchos problemas, pero al final la organización ha ido creciendo y sobrevive. Ahorita, como les comentaba el compañero de DECOTUX, ya hemos construido más de 150 viviendas. Para el próximo año habrá otras más y así seguimos. Entonces, ahí estamos viendo cosas, lo social, cositas, son pequeñas pero sí son importantes. Son como puntos rojos que tenemos marcados para trabajar, de acuerdo a que no tenemos muchas posibilidades económicas, pero a veces no tenemos casi ninguna posibilidad y siempre topamos con la burocracia, y todos esos obstáculos que nos ponen ellos, pero ahí vamos caminando. Las instituciones siempre prometen el agua para todos y si no hay, hasta el río también prometen, aunque no exista nada más que solo en los institutos demagógicos de ellos. Pero, entonces yo creo que este proyecto va creciendo y aquí estamos para cuando quieran venir a ver, aquí estamos, ¿no?, porque no nos dio tiempo de enseñarle todo, no porque hay cosas que merecen muy mucho la pena, ¿no? (Campesino nahua y representante del CICATH).

6.2. Primeros intentos de cooptación de las iniciativas alternativas interculturales por las lógicas desarrollistas neoliberales hegemónicas

Sin embargo, pese a todo lo expuesto en los dos epígrafes precedentes, el grado de autonomía de estos proyectos alternativos de la Sierra de Santa Marta en relación al sistema desarrollista hegemónico capitalista y sus necesidades es todavía casi inexistente. Además, existe un riesgo palpable de que estos proyectos cooperativos sean cooptados por las lógicas neoliberales en sus objetivos fundacionales y se desvirtúen con ello sus estructuras comunitarias solidarias.

Las iniciativas ciudadanas indígenas tienen todavía un alto contenido de resistencia, puesto que se oponen aún a la colonización de sus vidas y espacios que se sigue impulsando desde las instituciones en nombre de la modernización y del progreso y el "desarrollo". De esta forma, las minorías buscan a través de una nueva estructura reticular, heterogénea y multiforme de sus formas de participación y organización comunitaria, concertar los empeños de la gente, para protegerse de las amenazas de la naturaleza y la cultura planteadas por el "desarrollo" y la expansión económica que impulsan aún las estructuras dominantes: 
Mire, si los que están al frente de estos proyectos fueran priistas, del PRI [Partido Revolucionario Institucional], sí seguiría acudiendo el dinero y los recursos hasta los proyectos, pero como saben que eso no lo van a poder controlar políticamente, por eso más bien nos abandonan. Eso es lo que se está pretendiendo desde Dos Volcanes (Académica, intelectual activista y miembro fundador del PSSM).

Dos Volcanes es la denominación de un nuevo proyecto, coordinado por la Comisión Municipal de Agua Potable y Saneamiento de Coatzacoalcos (CMAS) y auspiciado principalmente por el gobernador del estado de Veracruz, Javier Duarte de Ochoa. El objetivo explícito de esta iniciativa gubernamental es "recuperar y conservar los ecosistemas y biodiversidad de la cuenca Texizapa-Ocotal", principales ríos que surten a la presa Yuribia.

Con las acciones propuestas, aseguran sus creadores, se busca mantener e incrementar los servicios ambientales que proveen, y con ello mejorar la disponibilidad y calidad del agua para los municipios de Coatzacoalcos, Minatitlán y Cosoleacaque. Al mismo tiempo, según afirman sus impulsores desde altas instancias de la administración estatal, planea generar beneficios para mejorar el nivel de vida de las comunidades indígenas campesinas dueñas de las tierras de la cuenca TexizapaOcotal en el corazón geográfico de la Sierra de Santa Marta:

La disponibilidad de agua en esta región se ha visto afectada debido a que los pozos han disminuido su nivel y durante la temporada de lluvias la cantidad de sedimentos en los arroyos genera turbiedades que afectan la calidad del líquido que llega a la planta potabilizadora, lo que reduce su capacidad al mínimo. Así surge este proyecto, que busca ayudar a que nuestros volcanes, principales encargados de encauzar el agua que todos aprovechamos, recuperen en la mayor medida posible lo que a lo largo de mucho tiempo han ido perdiendo. Dos Volcanes busca también involucrar en un proyecto conjunto a la sociedad civil, al gobierno y a la iniciativa privada. Con el objetivo de garantizar una fuente de recursos permanente para el proyecto, se invitará a participar a empresas de la región, con lo que se pondrá en marcha el Fondo Ambiental Yuribia A.C. (Comunicado en prensa de Dos Volcanes).

En principio, Dos Volcanes fue creado con el fin de mejorar la disponibilidad y calidad del agua que surte a la presa Yuribia, y con ello beneficiar a los habitantes de las ciudades de Coatzacoalcos, Minatitlán, Cosoleacaque, Jáltipan o Acayucan, pero también a aquellos que viven en las partes altas de la cuenca, los responsables de la captación de agua:

Es un proyecto grande con el cual trabajaremos en la remediación, reforestación y en una generación de proyectos productivos en aquella zona (Comunicación en prensa de Dos Volcanes). 
Después de la primera etapa de esta iniciativa gubernamental, que consistió en difundir información sobre sus características y múltiples beneficios, sus impulsores arrancan la segunda fase. La misma busca también mejoras ganaderas mediante técnicas silvopastoriles, producción de café de sombra y apoyo a la milpa tradicional, jornadas de reforestación, promoción de desarrollo comunitario mediante estufas ahorradoras de leña, así como proyectos productivos para la elaboración de productos gastronómicos típicos y artesanías:

Estamos convencidos de que existe una solución a los problemas hídricos de la cuenca Texizapa-Ocotal (al sur del estado) y consiste en unir esfuerzos, los ciudadanos, la iniciativa privada y el sector gobierno. Hoy, después de informar a la población de esta urgente necesidad, estamos a muy poco de enfocar nuestros esfuerzos directamente en las comunidades rurales. Podremos conservar y aprovechar de manera sustentable el vital recurso hídrico, además lograremos que en temporada de sequías se mantenga el abasto de agua, y por supuesto, que las generaciones futuras no enfrenten el problema de falta de agua; en pocas palabras, hoy sabemos que cuidar la naturaleza nos beneficia a todos y que es tiempo de hacer algo (Comunicación en prensa de Dos Volcanes).

Basta decir que este proyecto fue dado a conocer en sociedad entre grandes pompas. Se presentó en el marco del Día Mundial del Agua y el evento contó con la presencia de ilustres invitados especiales a la gala pertenecientes a distintos ámbitos de la sociedad mexicana, quienes, incluso, dieron pláticas sobre los objetivos "que se desean y que pueden lograrse, por muy lejanas que se vean las metas mientras se tenga la voluntad para hacerlo".

Se aclara desde el proyecto Dos Volcanes que esta iniciativa es algo que han estado "cocinando" desde hace 8 meses, y la primera etapa será de 5 años en la cual estarán trabajando de manera conjunta con la iniciativa privada la Asociación Civil Beta Diversidad que tienen una gran experiencia en la realización de proyectos de este tipo:

En su primera etapa será de 5 años y estamos para darle la sustentabilidad que se requiere y que no termine nunca, porque nunca vamos a dejar de necesitar del agua. Es por eso que estamos tardando tanto (Comunicación pública del coordinador y "vocero" - portavoz- de Dos Volcanes).

El desarrollo en campo de este proyecto, entre otros objetivos, contempla la reforestación de 400.000 ha para la completa restauración forestal de la cuenca del río Texizapa-Huazuntlán, de la cual se nutre el acueducto Yuribia. Con ello en los municipios de Mecayapan, Tatahuicapan de Juárez y Soteapan se prevé una notable generación de empleos a través de los trabajos de restauración de la flora con especies propias de la zona. Así, se tiene contemplado que un promedio de 700 personas distribuidas en diversas parcelas con manejo agroforestal se beneficien con este 
empleo que hará que árboles de ceiba, cedro, cocuite, roble, café, pimienta y policultivos de maíz, frijol y café vuelvan a plantarse en la zona y restaurar de esta manera la cuenca hidrológica que abastece a la presa de Yuribia.

Además, está proyectado la inminente creación de un gran vivero de plantas autóctonas para la reforestación que dejará pequeño el que ya existe en la comunidad de Ocotal Grande y que es gestionado de forma comunitaria por DECOTUX y CICATH.

Para estas y otras actuaciones se han aprobado invertir 12 millones de pesos en programas de reforestación. Por lo que respecta a CMAS, este organismo se ha comprometido a aportar 7 millones de pesos, lo que significa 1.400 .000 pesos anuales a un Fondo Ambiental que financiará los programas de reforestación de Dos Volcanes:

Dos Volcanes va a llegar y les va a ofrecer dinero a todos los compañeros que trabajan en los proyectos aquí en la Sierra de Santa Marta, y esta gente por muy convencidos que estén con sus proyectos tienen que comer y mantener a sus familias, ¿no?... Bueno, algunos de ellos, los fundadores, gerentes y representantes legales, técnicos y promotores campesinos más comprometidos probablemente no lo harán porque son gente muy convencida en lo que hacen, pero otros muchos, todos los campesinos e indígenas pobres que dicen: "Ahorita ya no nos llega el recurso", sí lo pueden hacer; pero de ser así de ningún modo se les puede criticar por eso, porque aquí la gente tiene muchas necesidades vitales que cubrir. Mira, si ellos tuvieran una visión política más global y estuvieran más representados en la esfera política y pudieran organizarse políticamente y tener representación política la situación sería bien distinta (Académica, intelectual, activista y miembro fundador del PSSM).

\section{Conclusiones}

Sobre la idea de posdesarrollo (Escobar, 1995: pássim) se ha dicho que señalaba hacia un futuro prístino en el que el desarrollo ya no existiría. Sin embargo, según el propio Escobar nada de eso pretendía tal noción, sino que intuía la posibilidad de "vislumbrar una era en la que el desarrollo dejase de ser principio central organizador de la vida social" (Escobar 2010: 45); más aún, vislumbraba que tal desplazamiento ya estaba aconteciendo en el presente.

Otro tanto ha ocurrido con el posliberalismo, como un espacio/tiempo en el que la vida social no estuviese completamente determinada por las premisas de la economía, lo individual, la racionalidad instrumental, la propiedad privada y demás factores que caracterizan al liberalismo y la modernidad.

Por lo tanto, el posdesarrollo no es una situación a la que se ha de llegar en el futuro, sino algo que está en permanente construcción. De modo semejante, el poscapitalismo implica considerar a la economía como constituida por diversas prácticas capitalistas, capitalistas alternativas y no capitalistas; supone un estado de 
las cosas en el que el capitalismo ya no es la fuerza económica hegemónica. En el poscapitalismo el dominio de la economía ya no está completa y naturalmente en manos del capitalismo, sino de un conjunto de economías: "solidaria, cooperativa, social, comunal y hasta criminal, que no pueden ser reducidas al capitalismo" (Gibson y Graham, 2006: pássim).

De manera sucinta, conforme al material empírico recogido durante el trabajo de campo de la investigación presentada en este artículo en los municipios de la Sierra de Santa Marta en Veracruz (México), el pos o post implica que el capitalismo pierde su centralidad en la definición de la economía, el liberalismo en la definición de sociedad y de lo político, y las expresiones estatales de poder en la definición de la matriz de las organizaciones sociales. Esto no quiere decir que el capitalismo, el liberalismo y las formas estatales dejen de existir, significa que "su centralidad discursiva y social ha sido parcialmente desplazada, permitiendo así ampliar la gama de experiencias sociales existentes que son consideradas alternativas válidas y creíbles a lo que hoy predomina" (Santos, 2007, citado en Escobar, 2010: 46).

Sin embargo, como reflejan los avances de este estudio en la Sierra de Santa Marta, trascender el desarrollo solamente será posible "fijando la atención en las culturas, los conocimientos y los imaginarios locales en la construcción de un futuro ajeno a la noción de desarrollo" (Bretón, 2010: 12). Por tanto, se hace necesario "fijar la atención en los márgenes del sistema, en las prácticas y proyectos locales, en las culturas substantivas realmente existentes e invisibilizadas por la meta del discurso desarrollista" (Escobar, 2004 citado en Bretón, 2010: 12) como las presentadas en este texto.

No obstante, el argumento sobre la posibilidad de órdenes económicos posliberales, poscapitalistas, pos-estatistas y/o posdesarrollistas es hasta ahora más un argumento sobre su potencialidad (en el campo de lo virtual) que sobre cómo son las cosas en realidad. Confirmando en este sentido las reflexiones de Escobar (2010), el posdesarrollo seguirá siendo una hipótesis de trabajo a perfeccionar y una declaración de posibilidad, y así se ha planteado en este texto, con ánimo de discusión y debate. De esta forma, incipientes proyectos alternativos como los de la Sierra de Santa Marta, articulan una potencialidad de cómo podría ser el mundo en otro contexto. Es en estos espacios locales donde "no solo se incuban, sino que se experimentan y analizan nuevos imaginarios e ideas acerca de cómo re-ensamblar lo socio-natural" (Escobar, 2010: 46-47).

En definitiva y con base en los datos empíricos cualitativos expuestos en este artículo se puede observar la capacidad que - si bien de momento no pueden ser valoradas en términos definitivos - tienen estas novedosas prácticas alternativas de gestión integral, sustentable e intercultural de recursos naturales en la Sierra de Santa Marta de cuestionar abiertamente la capacidad del crecimiento económico para superar el subdesarrollo y generar verdadero desarrollo (etnodesarrollo, participación, empoderamiento, sustentabilidad integral, etc.), entendido éste como un incremento en el bienestar integral de las personas. 
Por consiguiente, que las referidas nociones no son sólo presunciones teóricas y conceptuales asumidas en el marco teórico de este trabajo de investigación, sino que pueden deducirse de los discursos y las prácticas de algunos movimientos sociales no gubernamentales y/o civiles, de intelectuales próximos a tales movimientos $\mathrm{y}$, sobre todo, de los actores locales del área objeto de estudio empírico, ha quedado de manifiesto en este texto.

Así pues, la etnografía de estas experiencias alternativas ha puesto de relieve que desde un emergente diálogo/ecología de saberes y una gestión colaborativa interactoral, inter-lingüe y, por ende, inter-cultural, basada en la larga tradición latinoamericana de participación estrecha entre movimientos sociales y grupos de base, por un lado, e intelectuales y académicos activistas, por otro lado, en la Sierra de Santa Marta se está permitiendo sobrevivir dignamente a algunas comunidades indígenas campesinas en condiciones estructurales globales adversas.

De este modo, los datos y materiales empíricos que aquí se han expuesto, evidencian que en estas novedosas e innovadoras experiencias de gestión y manejo de recursos naturales en la Sierra de Santa Marta se presentan como posibles modelos alternativos (ecológicos, históricos, económicos, sociales, políticos, culturales y educativos) que en alguna medida pueden contribuir a la mejora de la precaria realidad, tanto ambiental, como demográfica y socioeconómica, de las comunidades indígenas campesinas del sureste veracruzano.

Estos proyectos alternativos de manejo de recursos naturales en la Sierra de Santa Marta, a partir de su gestión integral, sustentable e intercultural, irradian un pequeño rayo de esperanza en cuanto a las posibilidades reales de conservar el trabajo y mejorar la existencia de las personas que se encuentran en situación de resto o redundancia respecto a las necesidades del sistema económico capitalista hegemónico, "evitando, en buena medida, tener que recurrir a la emigración" (Moreno-Arriba, 2013: 210).

Se trata así de evitar en lo posible aquello que Castells (2002: pássim) ha definido como la "Sociedad 20:80", en virtud de la cual una quinta parte (el 20\%) de la población planetaria vivirá en la opulencia, en tanto las cuatro quintas partes restantes se verán condenadas a una lucha feroz por sobrevivir. En suma, se muestra cómo los recursos endógenos de las selvas tropicales mesoamericanas han permitido sobrevivir dignamente a diferentes comunidades indígenas campesinas en condiciones estructurales globales hostiles para los espacios, sociedades y culturas locales.

No obstante, hay que reiterar que el éxito de este tipo de proyectos alternativos y/o experimentales no puede ser juzgado en términos absolutos, ni de manera aislada, es decir, sin ubicarlos como el germen de los siguientes procesos que se retroalimentarán en ellos. De esta forma, si de los aciertos, los errores, las dificultades o las limitaciones se logran obtener lecciones para los mismos proyectos, las réplicas serán más factibles. 
Sin embargo, pese al contenido de resistencia de estas iniciativas alternativas frente a la neocolonización impuesta por el modelo hegemónico desarrollista neoliberal a través de la economía de mercado, el grado de autonomía de estos incipientes proyectos cooperativos interculturales en relación al sistema capitalista dominante es todavía casi inexistente, y podrían ser fácilmente cooptados por las lógicas y estructuras de poder imperantes.

\section{Bibliografía}

Amin, Samir (1990) Maldevelopment. Anatomy of a Global Failure. Londres: Zed Books.

Argueta, Arturo (2011) "El diálogo de saberes, una utopía realista”, en A. Argueta, E. Corona-M. y P. Hersch (coords.) Saberes colectivos y diálogo de saberes en México. México D.F.: UNAM, 495-510.

Ávila, Adriana, y Mateos, Laura Selene (2008) "Configuración de actores y discursos híbridos en la creación de la Universidad Veracruzana Intercultural". Trace, 53, 64-82. [Disponible en línea. URL: $<$ http://trace.revues.org/393>. Consultado el 10 de abril de 2014].

Blom, Franz, y Lafarge, Oliver (1926) Tribus y templos. México D.F.: INI.

Bonfil, Guillermo (1982) América Latina: etnodesarrollo y etnocidio. Costa Rica: FLACSO.

Bretón, Víctor (2010) “Introducción”, en V. Bretón (ed.) Saturno devora a sus hijos. Miradas críticas sobre el desarrollo y sus promesas. Barcelona: Icaria, 7-31.

Caillé, Alain (1996) "Salir de la economía". Cuadernos de Trabajo Social, núm. 9, 143-152.

Castells, Manuel (2002) La Era de la Información. México D.F.: Siglo XXI.

Chevalier, Jacques, y Buckles, Daniel (1995) Land without Gods: Process Theory. Maldevelopment, and the Mexican Nahuas. Londres: Zed Books.

Clastres, Pierre (1974) La sociéte contre l'état. París: Minuit.

CONANP-SEMARNAT (2006) Programa de Conservación y Manejo Reserva de la Biosfera Los Tuxtlas (México). México D.F., CONANP-SEMARNAT.

Coraggio, José Luis (2004) "Economía del trabajo", en D. A. Cattani (ed.) La otra economía. Buenos Aires: Altamira, 151-163.

Dietz, Gunther (2009) Multiculturalism, Interculturality and Diversity in Education: An Anthropological Approach. Muenster y Nueva York: Waxmann.

Dietz, Gunther, y Mateos Laura Selene (2010) "La etnografía reflexiva en el acompañamiento de procesos de interculturalidad educativa. Un ejemplo veracruzano". Cuicuilco, núm. 48, 107-131.

Dirzo, Rodolfo, y García, María del Carmen (1992) "Rates of deforestation in Los Tuxtlas, a neotropical area in southeast México". Conservation Biology, núm. 6, 84-90. 
Escobar, Arturo (1993) "The Limits of Reflexitivity: Politics in Anthropology's Post-writing culture era". Journal of Anthropological Research, vol. 49, núm. 4, 377-391.

Escobar, Arturo (1995) "El desarrollo sostenible: diálogo de discursos". Ecología Política, núm. 9, 7-25.

Escobar, Arturo (1998) La invención del Tercer Mundo. Construcción y deconstrucción del desarrollo. Bogotá: Grupo Editorial Norma

Escobar, Arturo (2000) "El lugar de la naturaleza y la naturaleza del lugar: Globalización o posdesarrollo", en A. Viola (comp.) Antropología del desarrollo: Teorías y estudios etnográficos en América Latina. Barcelona-Buenos Aires-México: Paidós, 169-216.

Escobar, Arturo (2007) "Worlds and Knowledges Otherwise: the Latin American Modernity/Coloniality Research Program”. Cultural Studies, vol. 21, núm. 2-3, 179-210.

Escobar, Arturo (2010) "América Latina en una encrucijada: ¿modernizaciones alternativas, posliberalismo o posdesarrollo?", en V. Bretón (ed.) Saturno devora a sus hijos. Miradas críticas sobre el desarrollo y sus promesas. Barcelona: Icaria, 33-86.

Esteva, Gustavo (2004) "Desarrollo", en A. Viola (comp.) Antropología del Desarrollo: Teorías y Estudios Etnográficos en América Latina. Barcelona - Buenos Aires - México D.F.: Paidós, 67-102.

Ferguson, James (1990) The Anti-politics Machine. Development, Depolitizacion and Bureaucratic Power in Lesotho. Cambridge: Cambridge University Press.

Friedman, John (1992) Empowerment. The Politics of Alternative Development. Massachusetts: Blackwell.

García Canclini, Néstor (2004) "Sociedades del conocimiento: la construcción intercultural del saber", en N. García Canclini (coord.) Diferentes, desiguales y desconectados: mapas de la interculturalidad. Barcelona: Gedisa, 181-194.

García Linera, Álvaro (2007) "Entrevista a Álvaro García Linera: «Evo simboliza el quiebre de un imaginario restringido a la subalternidad de los indígenas»". (Entrevista realizada por Maristella Svampa y Pablo Stefanoni). Osal, núm. 22, 143164.

Gibson, Catherine, y Graham, Julie (2006) A Postcapitalist Politics. Minneapolis: University of Minnesota Press.

Hale, Charles R. (2008) "Introduction", en Ch. R. Hale (coord.) Engaging Contradictions: Theory, Politics Sand Methods of Activist Scholarship. Berkeley: University of California Press, 1-30.

Haraway, Dona J. (1995) Ciencia, cyborgs y mujeres. La reinvención de la naturaleza. Madrid: Cátedra.

Harrison, Faye V. (1991) "Anthropology as an agent of transformation: introductory comments and queries", en F. V. Harrison (ed.) Decolonizing Anthropology: 
moving further toward and anthropology for liberation. Washington: Association of Black Anthropologist, 1-14.

Jiménez, Luis Manuel (2000) Desarrollo sostenible. Transición hacia la coevolución global. Madrid: Pirámide.

Kapp, Karl William (1978) "El carácter de un sistema abierto de la economía y sus implicaciones", en K. Dopfer (ed.) La economía del futuro. México: FCE, 126146.

Laville, Jean Louis (2000) L'économie solidaire. Une perspective internationale. París: Desclée de Brouwer.

Leff, Enrique (2003) "Racionalidad ambiental y diálogo de saberes: sentidos y senderos de un futuro sustentable". Desenvolvimento e Meio Ambiente, núm. 7, $13-40$.

Lipietz, Alain (2002) “Qu'est-ce que l'économie sociale et solidaire?”. Ponencia presentada en Etats Généraux de l'Ecologie Politique. Aix-en-Provence, 23 de febrero.

Martínez de Pisón, Eduardo (2004) "Las cuencas hidrográficas: revisión histórica de su uso como soporte físico de la regionalización". Ambienta, núm. 36, 44-49.

Massey, Doreen B. (2004) "Geographies of Responsability". Geografiska Annaler, vol. 86b, núm. 1, 5-18.

Mato, Daniel (2008) "No hay saber «universal», la colaboración intercultural es imprescindible". Alteridades, vol. 18, núm. 35, 101-116.

Mignolo, Walter (2005) "La colonialidad a lo largo y ancho: el hemisferio horizontal en el horizonte colonial de la modernidad", en E. Lander (comp.) La colonialidad del saber: eurocentrismo y ciencia sociales: perspectivas latinoamericanas. Buenos Aires: CLACSO, 55-85.

Moreno-Arriba, Jesús (2013) "La gestión comunitaria de recursos naturales, agrosilvopastoriles y pesqueros en la Sierra de Santa Marta en Veracruz (México): ¿un alternativa posible al discurso desarrollista y a la globalización capitalista?”. Universitas Humanística, núm. 75, 189-217.

Moreno-Arriba, Jesús (2014) "El diálogo de saberes en la gestión de recursos naturales en la Sierra de Santa Marta en Veracruz (México): una posible alternativa sustentable a la emigración en las comunidades indígenas del Istmo Veracruzano". Revista Internacional de Estudios Migratorios (RIEM), vol. 4, núm. 1, 71-104. [URL: <http://www.riem.es/espanol/ContadorArticulo.php?idart=41>. Consultado el 2 de Diceimbre de 2014].

Narotzky, Susana (2010) "Reciprocidad y capital social: modelos teóricos, políticas de desarrollo, economías alternativas. Una perspectiva antropológica", en V. Bretón (ed.) Saturno devora a sus hijos. Miradas críticas sobre el desarrollo y sus promesas. Barcelona: Icaria, 127-174.

Paré, Luisa, et al. (1997) La Reserva Especial de la Biosfera Sierra de Santa Marta, Veracruz: diagnóstico y perspectiva. México D.F.: UNAM-IIS. 
Paré, Luisa, y Lazos, Elena (2000) Miradas indígenas sobre una naturaleza entristecida: percepciones del deterioro ambiental entre los Nahuas del Sur de Veracruz. México D.F.: UNAM.

Polanyi, Karl (2013 [1944]) La Gran Transformación. México D.F.: Fondo de Cultura Económica.

Quijano, Aníbal (2000) "Colonialidad del poder y clasificación social”. Journal of World-Systems Research, vol. VI, núm. 2, 342-386.

Rahnema, Majid, y Bawtree, Victoria (1996) The post-development reader. Londres: Zed Books.

Rist, Gilbert (2002) El desarrollo: historia de una creencia occidental. Madrid: Los Libros de la Catarata.

Santos, Boaventura de Sousa (2004) Produzir para viver. Os caminhos da produção não capitalista. Porto: Edições Afrontamento.

Santos, Boaventura de Sousa (2005) La universidad en el siglo XXI: para una reforma democrática y emancipadora de la universidad. México D.F.: UNAMCEIICH.

Santos, Boaventura de Sousa (2006) "La Sociología de las Ausencias y la Sociología de las Emergencias: para una ecología de saberes", en B. de Sousa Santos (ed.) Renovar la teoría crítica y reinventar la emancipación social (encuentros en Buenos Aires). Buenos Aires: CLACSO, 13-42.

Santos, Boaventura de Sousa (2007) The Rise of the Global Left. London: Zed Books.

Sahlins, Marshall (1987 [1972]) La Economía de la Edad de Piedra. Madrid: Akal.

Slim, Hugo (1998) “¿Qué es el desarrollo?”, en M. B. Anderson (pres.) Desarrollo y diversidad social. Barcelona: Icaria, 65-70.

Speed, Shannon (2006) "Entre la antropología y los derechos humanos: hacia una investigación activista y críticamente comprometida". Alteridades, núm. 31, 7385.

Toledo, Víctor Manuel (2011) "Del «diálogo de fantasmas» al «diálogo de saberes»: conocimiento y sustentabilidad comunitaria", en A. Argueta, E. Corona-M. y P. Hersch (coords.) Saberes colectivos y diálogo de saberes en México. México D.F.: UNAM, 469-484.

Tortosa, José María (2001) El juego global: maldesarrollo y pobreza en el sistema mundial. Barcelona: Icaria.

Truman, Harry (1964 [1949]) Public Papers of the President of the States United, Harry S. Truman. Washington: U.S. Government Printing Office.

United Nations (1951) Measures for the Economic Development on Underdeveloped Countries. New York: United Nations (Department of Social and Economic Affairs).

Velasco, Honorio M., y Díaz de Rada, Ángel, (1997). La lógica de la investigación etnográfica. Un modelo de trabajo para etnógrafos de escuela. Madrid: Trotta. 
Velázquez, Emilia (2000) "Ganadería y poder político en la Sierra de Santa Marta", en E. Leonard y E. Velázquez (coords.) El Sotavento Veracruzano: Procesos sociales y dinámicas territoriales. México D.F.: CIESAS - IRD, 11-127.

Velázquez, Emilia (2013) "Migración interna indígena desde el Istmo veracruzano: nuevas articulaciones regionales". Liminar: Estudios Sociales y Humanísticos, vol. XI, núm. 2, 128-148.

Walsh, Catherine; García Linera, Álvaro, y Mignolo, Walter (2003) Interculturalidad, descolonización del estado y del conocimiento. Buenos Aires: Signo. 